\title{
Simultaneous Inversion of Source Spectra, Attenuation Parameters, and Site Responses: Application to the Data of the French Accelerometric Network
}

\author{
by Stéphane Drouet*, Sébastien Chevrot, Fabrice Cotton, and Annie Souriau
}

\begin{abstract}
Displacement spectra of earthquakes recorded by the French accelerometric network at regional scale are modeled as the product of source, propagation (including geometric and anelastic attenuation), and site effects. We use an iterative Gauss-Newton inversion to solve the nonlinear problem and retrieve these different terms. This method is easy to implement because the partial derivatives of the amplitude spectrum with respect to the different parameters have simple analytic forms. After convergence, we linearize the problem around the solution to compute the correlation matrix, which allows us to identify the parameters which are poorly resolved. We analyze data from two tectonically active regions: the Alps and the Pyrenees. Eighty-three earthquakes with local magnitudes between 3.0 and 5.3 are analyzed, with epicentral distances in the range $15-200 \mathrm{~km}$. $S$-wave displacement spectra are computed using a fast Fourier transform and integration in the $0.5-15-\mathrm{Hz}$ frequency domain. We assume a Brune-type source, with a geometric attenuation of the form $R^{-\gamma}, \gamma$ being constant, and a frequency-dependent quality factor of the form $Q=Q_{0} \times f^{\alpha}$. The results reveal that the attenuation parameters are correlated to each other and to the seismic moments. The two regions have different attenuation patterns. The geometrical spreading factor is equal to 1 for the Alps and 1.2 for the Pyrenees. The anelastic attenuation exhibits low $Q_{0}$ values (322 and 376 for the Alps and the Pyrenees, respectively) with regional variations for $\alpha(0.21$ in the Alps and 0.46 in the Pyrenees). Computed moment magnitudes are generally 0.5 unit smaller than local magnitudes, and the logarithms of the corner frequencies decrease linearly with magnitude according to $\log _{10}\left(f_{c}\right)=1.72-0.32 \times M_{\mathrm{w}}$. Stress drops range from $10^{5}$ to $10^{7} \mathrm{~Pa}$ (i.e., 1-100 bars), with a slight dependence to magnitude (large stress drops for large magnitudes). Finally, robust site responses relative to an average rock-site response are derived, allowing us to identify good reference rock sites.
\end{abstract}

\section{Introduction}

In regions of low to moderate seismicity, as is the case in France, strong motion prediction is generally based upon extrapolation of weak-motion modeling, with extrapolations implying nonlinear processes (Bay et al., 2005). Attenuation and site responses are crucial parameters to perform such a prediction. Another important parameter that requires careful determination is the seismic moment. For historical and practical reasons, several magnitude scales are used to characterize small events, based on either record duration, $S$-wave amplitude, or on the coda decay. Moment magnitudes are

*Present address: Institute of Engineering Seismology and Earthquake Engineering, 46 Georgikis Scholis Str., Thessaloniki, P.O. Box 53, GR-55102 Finikas, Thessaloniki, Greece. now widely used for large events, but their determination for small events still leads to variable results.

In a previous study (Drouet et al., 2005), we used a twostep linear inversion adapted from Scherbaum and Wyss (1990) to retrieve the source, propagation, and site terms. This method was applied to accelerometric data collected by the Réseau Accélérométrique Permanent (i.e., French Accelerometric Network, RAP) in the French Pyrenees. However, the linearization process required several simplifications in the formalization of the problem, in particular an anelastic attenuation that is not frequency dependent. In addition, this method did not resolve some parameters that are strongly correlated, such as attenuation parameters and corner frequencies, or attenuation parameters and seismic moments. 
Several other studies deal with such inversion of source, propagation, and site terms. Some authors used information from one particular frequency to linearize the inversion (Bonilla et al., 1997; Malagnini and Herrmann, 2000). Frankel et al. (1999) used a nonlinear inversion to retrieve source and site terms after correcting for attenuation using a body-wave geometrical decay and a quality factor adapted to the region under study.

Here, we propose to use a similar Gauss-Newton method to invert simultaneously the different parameters describing propagation, sources, and sites. The problem is nonlinear because of the form of the source excitation and of the frequency-dependent quality factor. Following the classical approach, the amplitude spectra are expressed as a product of source, propagation, and site terms. The Gauss-Newton method starts from an a priori model and explores iteratively the model space, using the partial derivatives of the amplitude spectrum with respect to the different parameters that are computed at each step. In addition, we can compute the correlation matrix, which allows us to estimate the trade-off between the parameters and to identify those that are poorly resolved. We have applied this method to the accelerometric data for two tectonically active regions: the Alps and the Pyrenees. The application to the Pyrenean data will allow us to compare our results with those obtained with the linear method previously used (Drouet et al., 2005).

\section{The French Context}

France is a country of low to moderate seismicity. The strongest earthquakes occur principally in the Rhine Graben, the Alps, the Pyrenees, and the western part of France where only two accelerometers are currently installed. The other regions are characterized by a lower level of activity. Figure 1 shows the seismic activity in the French national territory for the period 1984-2004 as given by the Bureau Central Sismologique Français (BCSF). The deformation rates within

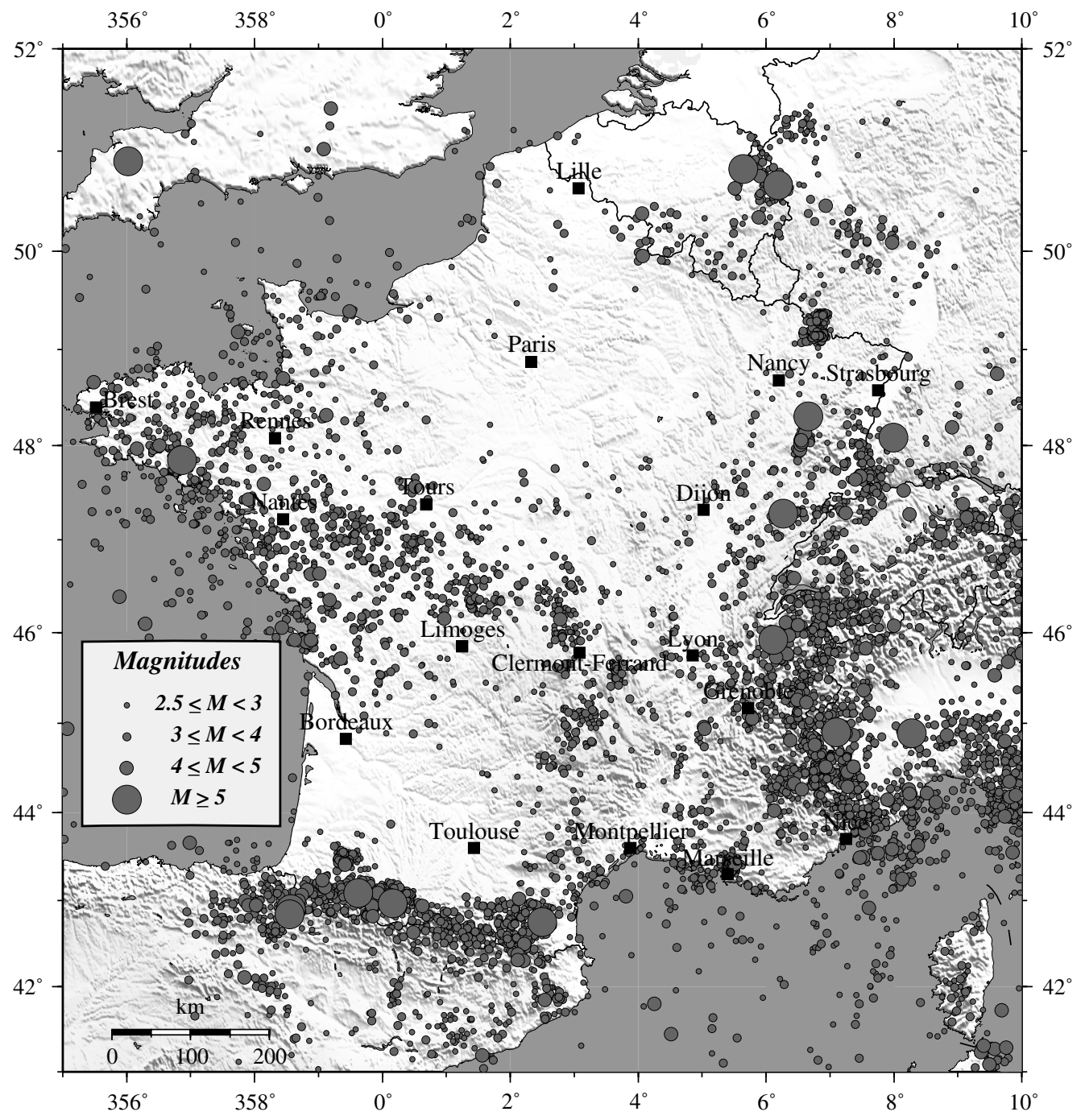

Figure 1. Seismic activity in France given by the BCSF for the period 1984-2004. 
France are low, of the order of a few millimeters per year, as inferred by Global Positioning System (GPS) measurements (Nocquet and Calais, 2003). However, evidence of strong earthquakes $(M \sim 6)$ with large recurrence times is found in the historical seismicity (Lambert and Levret-Albaret, 1996), and the two regions analyzed in this study were struck by such events in the past.

The RAP accelerometric network has been operating in France since 1996. It is managed by several institutions, and the data are freely accessible at www-rap.obs.ujf-grenoble.fr. There are 109 stations now deployed in the French metropolitan territory and another 20 in the Lesser Antilles (Martinique and Guadeloupe). The number of stations has increased since 2000, and a large database of moderate earthquakes is now available.

Several magnitude scales are currently used to characterize the seismicity in France. At the national level, the Réseau National de Surveillance Sismique (RéNaSS) at Strasbourg uses a magnitude scale ( $\left.M_{\text {RéNasS }}\right)$ based on the maximum amplitude of the vertical component with a specific amplitude decay of the form $a \Delta^{b}$, with $\Delta$ the epicentral distance and $a, b$ constants, compatible with Richter's $M_{\mathrm{L}}$ scale. The Laboratoire de Détection Géophysique (LDG) of the Atomic Energy Commission has defined another magnitude scale $\left(M_{\mathrm{LDG}}\right)$ based on the amplitude of the $L g$ wave at distances between 100 and $500 \mathrm{~km}$, with a distance correction defined for the whole national territory. Defining an appropriate amplitude decay in order to determine a momentbased magnitude scale is one of the goals of this study.

Numerous studies of crustal attenuation have been conducted in France. Modiano and Hatzfeld (1982) used the high frequency part of Fourier spectra, assuming a source decay as $f^{-2}$, to estimate a constant quality factor. Thouvenot (1983) used ray integrals and a depth-dependent quality factor to compute anelastic attenuation for compressional waves. Other authors used the decay of $L g$ waves at large distance in order to estimate a frequency-dependent quality factor (Nicolas et al., 1982; Campillo et al., 1985; Campillo and Plantet, 1991), or the decay of coda waves (Herráiz and Mezcua, 1984; Gagnepain-Beyneix, 1987; Eva et al., 1991), where the single scattering model is used. The different attenuation models obtained for France are summarized in Table 1. These different studies found $Q$-values between 100 and 1000 , but large values of $Q_{0}$ were generally associated with low values for $\alpha$, suggesting a strong trade-off between these two parameters. Quantifying these correlations between attenuations parameters is also a goal of the present study.

One of the critical factors in the accurate determination of earthquake source parameters and estimation of seismic hazard is detailed information on site response. The actual site classification of the French accelerometric stations is based on geological maps and visual description of sites. According to Steidl et al. (1996), instruments located on apparently competent bedrock may not be good reference sites with a flat amplitude response in the frequencies of engineering interest. One of the goals of our study is to determine site effects of each individual French accelerometric station and to identify reference stations having a transfer function similar to that expected for a rock site. Reference sites where accelerometric stations are now installed have been used to evaluate local site effects in large cities (Grenoble, Nice) with site-to-reference spectral ratio methods (Semblat et al., 2000; Le Brun et al., 2001) or to assess rock ground motion models (Scherbaum et al., 2004). The critical assumption in these studies is that the surface-rock-site record (reference) at these stations is equivalent to the input motion at the base of the soil layers, and that these particular rock sites have a flat transfer function. We will assess the validity of this assumption.

\section{Data Selection and Spectrum Computation}

Two data sets have been constructed for two regions of France: the Alps and the Pyrenees. For these two regions, the data sets consist of earthquakes with local magnitudes larger than 3 and recorded by at least three RAP stations. This selection results in 55 earthquakes in the Alps and 28 earthquakes in the Pyrenees. Records corresponding to distances between 15 and $200 \mathrm{~km}$ are kept. Figure 2 presents the location of the two regions with earthquake epicenters, stations,

Table 1

Summary of the Major Results on Anelastic Attenuation in France $\left(Q(f)=Q_{0} f^{\alpha}\right)$

\begin{tabular}{|c|c|c|c|c|c|}
\hline Authors & $Q_{0}$ & $\alpha$ & Frequency band $(\mathrm{Hz})$ & Wave Type & Region \\
\hline Herráiz and Mezcua (1984) & 557 & & $1.4-2.8$ & Coda & Pyrenees \\
\hline Modiano and Hatzfeld (1982) & $180-350$ & & $15-50$ & $S g$ & Pyrenees \\
\hline Nicolas et al. (1982) & 100 to 1000 depending on $f$ & 0.8 & $0.5-16$ & $\mathrm{Pn}, \mathrm{SnPg}, \mathrm{Sg}$ & France \\
\hline Thouvenot (1983) & 180 to 1600 depending on depth & 0.25 & 20 for $Q_{0} 10$ to 20 for $\alpha$ & $\mathrm{Pn}$ & Alps \\
\hline Gagnepain-Beyneix (1987) & $30-142$ & $0.7-1.1$ & $2-40$ & Coda & Pyrenees \\
\hline Eva et al. (1991) & 100 to 1000 depending on $f$ & & $2-16$ & Coda & Alps \\
\hline Campillo et al. (1985) & 290 & 0.5 & $0.5-10$ & $L g$ & France \\
\hline Campillo and Plantet (1991) & 320 & 0.5 & $0.5-10$ & $L g$ & France \\
\hline This study & 322 & 0.21 & $0.5-15$ & $S g$ & Alps \\
\hline$\gamma=1.0$ & & & & & \\
\hline $\begin{array}{l}\text { This study } \\
\gamma=1.2\end{array}$ & 376 & 0.46 & $0.5-15$ & $S g$ & Pyrenees \\
\hline
\end{tabular}



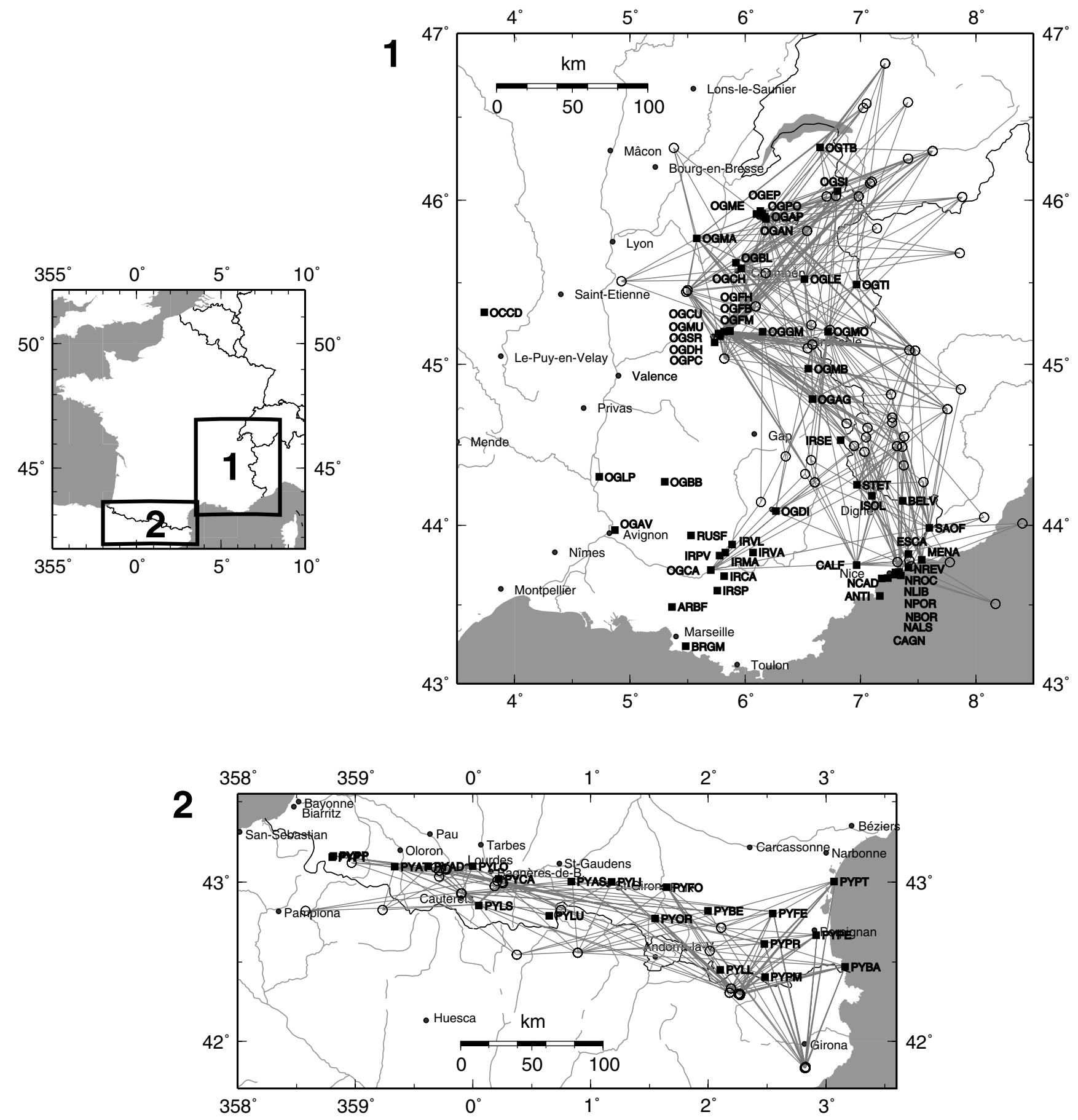

Figure 2. Maps of the two regions under study with earthquakes (circles), stations (squares), and paths (gray lines) analyzed. Alps, 1; Pyrenees, 2.

and paths. In Figure 3, we plot the recording distances for each station for the two areas. One can see that each station records earthquakes at various distances and that there is no obvious bias of recording distance with magnitude (open triangles are earthquakes with $M_{\text {RéNass }}$ lower than or equal to 3.5 , and black triangles are earthquakes with $M_{\text {RéNass }}$ greater than 3.5). Table 2 lists the stations and Tables 3 and 4 list the earthquakes that are used in this study.
We compute the Fourier spectrum of each record after removing the linear trend. The spectra are then divided by $\omega^{2}$ (where $\omega=2 \pi f$, with $f$ the frequency) in order to obtain displacement spectra. The spectra are finally smoothed between 0.5 and $30 \mathrm{~Hz}$. The smoothing is performed by computing the mean value over frequency bands with a constant width in a logarithmic scale in order to lower the level of high-frequency fluctuations in the spectra. 

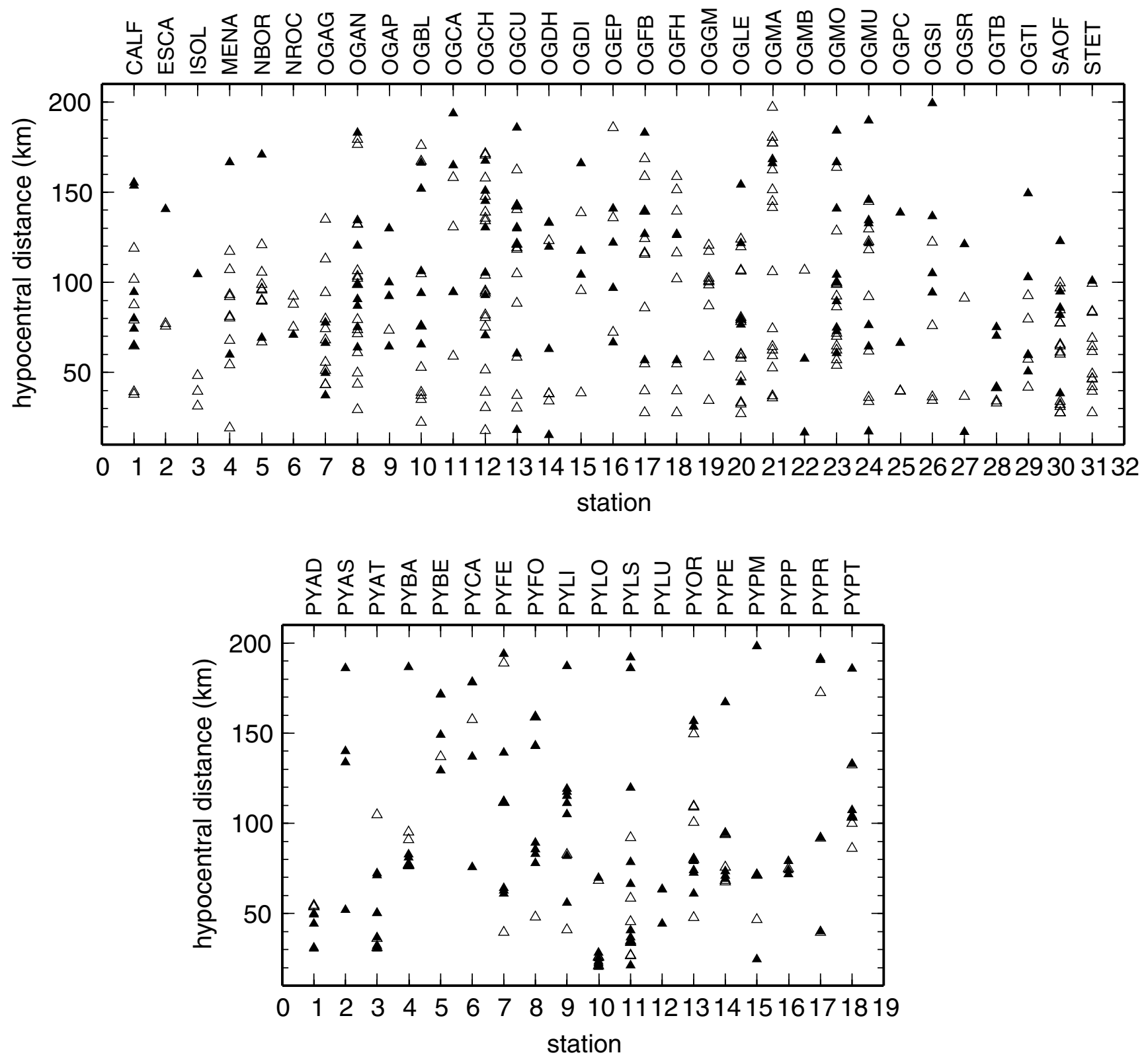

Figure 3. Recording distances as a function of station for earthquakes with RéNaSS magnitude $\leq 3.5$ (open triangles), and earthquakes with RéNaSS magnitude $>3.5$ (black triangles).

The east-west and north-south components are combined in the Fourier domain to obtain a single horizontal component:

$$
S(H)=\sqrt{S(E)^{2}+S(N)^{2}}
$$

In some studies, the root mean square of the two components is used. Depending on the correlation between the eastwest and north-south components, the difference between the two approaches may lead to a systematic difference in the moment magnitude or in the logarithms of the site effect by a factor that does not exceed $\log _{10}(\sqrt{2})$.
Noise spectra are computed in the same way as signal spectra, from the beginning of the record to the $P$-wave arrival time. A minimum signal-to-noise ratio of 3 is imposed at any frequency used in the inversion.

Acceleration waveforms for the east-west and northsouth components of the 8 November 1997 earthquake (number 5 in Table 3) at stations SAOF, CALF, and OGCA are shown in Figure 4, as well as the raw and smoothed displacement spectra for $S$ waves and noise. The displacement spectra of $S$ waves reveal a rather flat level for frequencies greater than approximately $0.4 \mathrm{~Hz}$ followed by a decay at high frequency. A strong increase is also observed at very low frequency, owing to division by $\omega^{2}$ or instrumental noise. 
Table 2

Accelerometric Stations from the RAP Used in This Study

\begin{tabular}{|c|c|c|c|c|c|}
\hline Name & Latitude $\left({ }^{\circ} \mathrm{N}\right)$ & Longitude $\left({ }^{\circ} \mathrm{E}\right)$ & Altitude $(\mathrm{m})$ & Geological Site Classification & Installation Date (DD/MM/YYYY) \\
\hline \multicolumn{6}{|c|}{ RAP Stations in the Alps } \\
\hline CALF & 43.751 & 6.919 & 1242 & rock & $30 / 10 / 1995$ \\
\hline ESCA & 43.820 & 7.368 & 550 & rock & $30 / 10 / 2003$ \\
\hline ISOL & 44.184 & 7.050 & 910 & rock & $17 / 09 / 2003$ \\
\hline MENA & 43.784 & 7.485 & 210 & rock & 09/02/1999 \\
\hline NBOR & 43.686 & 7.301 & 191 & rock & 07/05/1998 \\
\hline NROC & 43.706 & 7.287 & 22 & sediment & 07/05/1998 \\
\hline OGAG & 44.788 & 6.540 & 1307 & rock & 09/06/1995 \\
\hline OGAN & 45.892 & 6.136 & 468 & rock & $18 / 02 / 1997$ \\
\hline OGAP & 45.904 & 6.133 & 467 & sediment & $05 / 02 / 1998$ \\
\hline OGBL & 45.621 & 5.871 & 192 & sediment & $01 / 09 / 1998$ \\
\hline OGCA & 43.718 & 5.654 & 400 & rock & $13 / 06 / 1996$ \\
\hline $\mathrm{OGCH}$ & 45.585 & 5.919 & 525 & rock & 01/07/1997 \\
\hline OGCU & 45.200 & 5.770 & 212 & sediment & $18 / 06 / 1997$ \\
\hline OGDH & 45.172 & 5.734 & 212 & sediment & $17 / 04 / 1996$ \\
\hline OGDI & 44.089 & 6.218 & 770 & rock & $21 / 04 / 1996$ \\
\hline OGEP & 45.934 & 6.084 & 490 & sediment & $21 / 03 / 2002$ \\
\hline OGFB & 45.203 & 5.818 & 220 & sol & $15 / 12 / 2000$ \\
\hline OGFH & 45.203 & 5.818 & 220 & sediment & $19 / 12 / 2000$ \\
\hline OGGM & 45.200 & 6.104 & 1575 & rock & $11 / 05 / 1995$ \\
\hline OGLE & 45.521 & 6.468 & 639 & rock & $05 / 12 / 1997$ \\
\hline OGMA & 45.769 & 5.534 & 670 & rock & $21 / 04 / 1999$ \\
\hline OGMB & 44.971 & 6.500 & 1460 & rock & $25 / 09 / 1998$ \\
\hline OGMO & 45.200 & 6.671 & 1200 & rock & $07 / 10 / 1996$ \\
\hline OGMU & 45.188 & 5.720 & 250 & rock & $23 / 01 / 1997$ \\
\hline OGPC & 45.135 & 5.689 & 215 & sediment & 08/01/1998 \\
\hline OGSI & 46.054 & 6.754 & 750 & rock & 03/05/1996 \\
\hline OGSR & 45.187 & 5.736 & 212 & sediment & $10 / 07 / 1996$ \\
\hline OGTB & 46.318 & 6.602 & 860 & sol & 08/02/1999 \\
\hline OGTI & 45.487 & 6.919 & 1796 & rock & $21 / 01 / 1998$ \\
\hline SAOF & 43.984 & 7.551 & 595 & rock & $27 / 04 / 1995$ \\
\hline STET & 44.253 & 6.921 & 1200 & rock & $27 / 11 / 1996$ \\
\hline \multicolumn{6}{|c|}{ RAP Stations in the Pyrenees } \\
\hline PYAD & 43.097 & -0.426 & 450 & rock & $02 / 02 / 2001$ \\
\hline PYAS & 43.012 & 0.797 & 430 & sediment & $19 / 06 / 2002$ \\
\hline PYAT & 43.095 & -0.711 & 340 & rock & $24 / 04 / 2001$ \\
\hline PYBA & 42.469 & 3.117 & 70 & rock & $15 / 04 / 2002$ \\
\hline PYBE & 42.820 & 1.952 & 1080 & rock & $04 / 10 / 2001$ \\
\hline PYCA & 43.024 & 0.182 & 701 & rock & $20 / 08 / 2003$ \\
\hline PYFE & 42.814 & 2.502 & 275 & rock & $22 / 12 / 2000$ \\
\hline PYFO & 42.967 & 1.602 & 380 & sediment & $21 / 12 / 2000$ \\
\hline PYLI & 43.001 & 1.134 & 424 & rock & $16 / 04 / 2002$ \\
\hline PYLO & 43.098 & -0.048 & 410 & rock & $24 / 07 / 2001$ \\
\hline PYLS & 42.854 & 0.003 & 770 & rock & $30 / 07 / 2001$ \\
\hline PYLU & 42.791 & 0.601 & 630 & sediment & $14 / 08 / 2001$ \\
\hline PYOR & 42.772 & 1.502 & 1030 & rock & $26 / 09 / 2002$ \\
\hline PYPE & 42.669 & 2.871 & 100 & rock & $08 / 06 / 2001$ \\
\hline PYPM & 42.406 & 2.435 & 920 & rock & $20 / 12 / 2000$ \\
\hline PYPP & 43.163 & -1.232 & 230 & rock & $15 / 07 / 2002$ \\
\hline PYPR & 42.614 & 2.429 & 410 & rock & $23 / 05 / 2001$ \\
\hline PYPT & 43.003 & 3.023 & 60 & rock & $27 / 08 / 2001$ \\
\hline
\end{tabular}

However, it is hard to define the high and low frequency asymptotes that define the corner frequency and the seismic moment of the event.

It is important to note that the $S$-wave spectra depend significantly on the window length that is used to extract the $S$ waves. Authors concerned with attenuation select generally narrow windows around the $S$ arrival (e.g., Castro et al.,
2003), whereas those concerned with site effects use longer windows in order to catch more energy (Seekins et al., 1996; Castro et al., 2004). We choose to use time windows beginning $1 \mathrm{sec}$ before the $S g$ arrival with a duration of $5 \mathrm{sec}$, which seemed to be a good compromise between the need to select mostly $S g$ waves and exclude the other phases and the need to get enough energy to compute the 
Table 3

Earthquakes in the Alps Area

\begin{tabular}{|c|c|c|c|c|c|c|c|c|c|c|c|}
\hline \multirow[b]{2}{*}{ Event } & \multirow[b]{2}{*}{ Year } & \multirow[b]{2}{*}{ Month } & \multirow[b]{2}{*}{ Day } & \multirow[b]{2}{*}{ Time } & \multirow[b]{2}{*}{ Latitude $\left({ }^{\circ} \mathrm{N}\right)$} & \multirow[b]{2}{*}{ Longitude $\left({ }^{\circ} \mathrm{E}\right)$} & \multirow[b]{2}{*}{ Depth $(\mathrm{km})$} & \multicolumn{2}{|c|}{ Magnitudes } & \multirow[b]{2}{*}{ Number } & \multirow[b]{2}{*}{$\Delta(\mathrm{km}) \mathrm{Min} / \mathrm{Max}$} \\
\hline & & & & & & & & LDG & RéNaSS & & \\
\hline 1 & 1997 & 5 & 15 & $00 \mathrm{~h} 24 \mathrm{~m}$ & 45.210 & 6.686 & 8.4 & 3.8 & 4.1 & 4 & $48.7 / 94.0$ \\
\hline 2 & 1997 & 10 & 3 & $15 \mathrm{~h} 03 \mathrm{~m}$ & 44.321 & 6.472 & 13.9 & 3.8 & 4.0 & 3 & $72.8 / 99.0$ \\
\hline 3 & 1997 & 10 & 31 & $04 \mathrm{~h} 23 \mathrm{~m}$ & 44.268 & 6.554 & 6.2 & 4.7 & 4.8 & 10 & $64.5 / 199.2$ \\
\hline 4 & 1997 & 11 & 6 & $12 \mathrm{~h} 39 \mathrm{~m}$ & 44.407 & 6.525 & 9.2 & 3.6 & 3.7 & 3 & $79.4 / 94.4$ \\
\hline 5 & 1997 & 11 & 8 & $01 \mathrm{~h} 56 \mathrm{~m}$ & 44.070 & 7.890 & 2.0 & - & 4.1 & 4 & $38.6 / 193.6$ \\
\hline 6 & 1997 & 12 & 10 & $21 \mathrm{~h} 36 \mathrm{~m}$ & 43.790 & 7.500 & 8.0 & - & 3.3 & 3 & $27.8 / 84.0$ \\
\hline 7 & 1998 & 3 & 30 & $20 \mathrm{~h} 49 \mathrm{~m}$ & 46.640 & 7.230 & 10.0 & - & 3.2 & 3 & $75.8 / 163.6$ \\
\hline 8 & 1998 & 4 & 11 & $11 \mathrm{~h} 05 \mathrm{~m}$ & 44.671 & 7.229 & 14.0 & 4.0 & 3.8 & 7 & $73.4 / 164.3$ \\
\hline 9 & 1998 & 5 & 6 & $12 \mathrm{~h} 02 \mathrm{~m}$ & 44.150 & 6.010 & 10.0 & - & 3.2 & 3 & $58.9 / 117.3$ \\
\hline 10 & 1998 & 5 & 13 & $21 \mathrm{~h} 11 \mathrm{~m}$ & 44.450 & 6.300 & 5.0 & - & 3.1 & 3 & $38.7 / 87.0$ \\
\hline 11 & 1999 & 1 & 11 & $03 \mathrm{~h} 36 \mathrm{~m}$ & 45.036 & 5.772 & 0.2 & 4.2 & 4.1 & 13 & $15.4 / 189.3$ \\
\hline 12 & 1999 & 2 & 14 & $05 \mathrm{~h} 57 \mathrm{~m}$ & 46.820 & 7.166 & -0.2 & 4.7 & 3.8 & 7 & $70.5 / 184.1$ \\
\hline 13 & 1999 & 4 & 25 & $20 \mathrm{~h} 36 \mathrm{~m}$ & 45.910 & 6.970 & 2.0 & - & 3.0 & 3 & $36.4 / 124.8$ \\
\hline 14 & 1999 & 4 & 30 & $20 \mathrm{~h} 59 \mathrm{~m}$ & 44.010 & 7.970 & 2.0 & - & 3.2 & 3 & $64.7 / 119.0$ \\
\hline 15 & 1999 & 6 & 10 & $16 \mathrm{~h} 16 \mathrm{~m}$ & 45.650 & 6.060 & 2.0 & - & 3.1 & 4 & $16.9 / 52.2$ \\
\hline 16 & 1999 & 8 & 28 & $15 \mathrm{~h} 03 \mathrm{~m}$ & 45.260 & 6.480 & 2.0 & - & 3.3 & 4 & $31.6 / 66.4$ \\
\hline 17 & 1999 & 9 & 13 & $23 \mathrm{~h} 27 \mathrm{~m}$ & 45.444 & 5.442 & 4.0 & 4.0 & 3.5 & 10 & $36.8 / 122.3$ \\
\hline 18 & 1999 & 11 & 1 & $17 \mathrm{~h} 22 \mathrm{~m}$ & 43.780 & 7.360 & 4.0 & - & 3.3 & 4 & $17.0 / 130.3$ \\
\hline 19 & 2000 & 4 & 1 & $01 \mathrm{~h} 21 \mathrm{~m}$ & 45.086 & 7.377 & 3.2 & 3.1 & 3.0 & 5 & $56.8 / 126.7$ \\
\hline 20 & 2000 & 4 & 5 & $8 \mathrm{~h} 38 \mathrm{~m}$ & 45.508 & 4.880 & 8.8 & 3.4 & 3.2 & 5 & $58.5 / 123.7$ \\
\hline 21 & 2000 & 5 & 31 & $07 \mathrm{~h} 46 \mathrm{~m}$ & 44.814 & 7.219 & 12.9 & 3.5 & 3.2 & 6 & $54.0 / 146.3$ \\
\hline 22 & 2000 & 6 & 10 & $02 \mathrm{~h} 44 \mathrm{~m}$ & 44.552 & 7.330 & 3.2 & 3.5 & 3.2 & 6 & $46.5 / 142.5$ \\
\hline 23 & 2000 & 6 & 26 & $19 \mathrm{~h} 29 \mathrm{~m}$ & 44.497 & 6.897 & 4.4 & 3.6 & 3.3 & 8 & $27.2 / 177.3$ \\
\hline 24 & 2000 & 8 & 19 & $08 \mathrm{~h} 37 \mathrm{~m}$ & 46.023 & 6.659 & 1.8 & 4.0 & 3.5 & 6 & $33.1 / 118.9$ \\
\hline 25 & 2000 & 12 & 19 & $14 \mathrm{~h} 20 \mathrm{~m}$ & 43.743 & 7.393 & 8.8 & 3.7 & 3.4 & 4 & $29.6 / 134.5$ \\
\hline 26 & 2000 & 12 & 20 & $05 \mathrm{~h} 45 \mathrm{~m}$ & 43.781 & 7.377 & 7.3 & 3.2 & 3.0 & 3 & $26.5 / 130.2$ \\
\hline 27 & 2001 & 1 & 25 & $02 \mathrm{~h} 17 \mathrm{~m}$ & 46.027 & 6.741 & 3.3 & 3.3 & 3.0 & 9 & $34.1 / 123.2$ \\
\hline 28 & 2001 & 2 & 23 & $22 \mathrm{~h} 19 \mathrm{~m}$ & 46.110 & 7.050 & 2.8 & 3.9 & 3.6 & 8 & $41.5 / 145.6$ \\
\hline 29 & 2001 & 2 & 25 & $01 \mathrm{~h} 22 \mathrm{~m}$ & 46.101 & 7.036 & 4.9 & 3.5 & 3.2 & 6 & $41.2 / 144.1$ \\
\hline 30 & 2001 & 3 & 14 & $07 \mathrm{~h} 09 \mathrm{~m}$ & 43.500 & 7.940 & 8.0 & 4.1 & 3.8 & 4 & $59.9 / 166.0$ \\
\hline 31 & 2001 & 5 & 30 & $22 \mathrm{~h} 43 \mathrm{~m}$ & 45.814 & 6.488 & 6.1 & 3.6 & 3.3 & 11 & $28.6 / 91.8$ \\
\hline 32 & 2001 & 7 & 1 & $19 \mathrm{~h} 37 \mathrm{~m}$ & 44.580 & 7.030 & 5.0 & 3.7 & 3.4 & 3 & $17.6 / 121.2$ \\
\hline 33 & 2001 & 10 & 16 & $04 \mathrm{~h} 18 \mathrm{~m}$ & 45.098 & 6.496 & 6.2 & 3.4 & 3.1 & 6 & $47.1 / 105.8$ \\
\hline 34 & 2002 & 1 & 20 & $07 \mathrm{~h} 35 \mathrm{~m}$ & 44.373 & 7.328 & 12.7 & 3.5 & 3.0 & 3 & $66.7 / 152.3$ \\
\hline 35 & 2002 & 4 & 21 & $17 \mathrm{~h} 57 \mathrm{~m}$ & 45.680 & 7.815 & 0.0 & 3.5 & 3.3 & 4 & $106.3 / 177.3$ \\
\hline 36 & 2002 & 5 & 6 & $06 \mathrm{~h} 42 \mathrm{~m}$ & 44.490 & 7.270 & 5.0 & 3.5 & 3.0 & 5 & $40.8 / 157.8$ \\
\hline 37 & 2002 & 5 & 31 & $16 \mathrm{~h} 50 \mathrm{~m}$ & 46.251 & 7.366 & -1.1 & 3.6 & 3.5 & 4 & $103.3 / 151.3$ \\
\hline 38 & 2003 & 2 & 4 & $20 \mathrm{~h} 49 \mathrm{~m}$ & 46.050 & 7.770 & 5.0 & 3.6 & 3.4 & 6 & $92.5 / 180.3$ \\
\hline 39 & 2003 & 3 & 10 & $13 \mathrm{~h} 25 \mathrm{~m}$ & 44.850 & 7.810 & 10.0 & 3.5 & 3.1 & 4 & $98.1 / 175.5$ \\
\hline 40 & 2003 & 4 & 29 & $04 \mathrm{~h} 55 \mathrm{~m}$ & 46.320 & 7.590 & 5.0 & 4.2 & 3.9 & 11 & $75.1 / 189.7$ \\
\hline 41 & 2003 & 5 & 25 & $23 \mathrm{~h} 03 \mathrm{~m}$ & 45.120 & 6.500 & 5.0 & 4.0 & 3.6 & 20 & $16.8 / 170.8$ \\
\hline 42 & 2003 & 6 & 10 & $22 \mathrm{~h} 59 \mathrm{~m}$ & 44.789 & 7.700 & 5.0 & 3.8 & 3.4 & 14 & $81.4 / 197.2$ \\
\hline 43 & 2003 & 8 & 17 & $22 \mathrm{~h} 31 \mathrm{~m}$ & 44.650 & 6.860 & 5.0 & 3.4 & 3.2 & 4 & $64.3 / 162.2$ \\
\hline 44 & 2003 & 9 & 1 & $19 \mathrm{~h} 28 \mathrm{~m}$ & 44.260 & 7.440 & 5.0 & 3.7 & 3.4 & 5 & $32.1 / 178.8$ \\
\hline 45 & 2003 & 10 & 16 & $16 \mathrm{~h} 23 \mathrm{~m}$ & 44.620 & 7.010 & 5.0 & 3.4 & 3.1 & 4 & $47.2 / 120.5$ \\
\hline 46 & 2003 & 12 & 2 & $17 \mathrm{~h} 08 \mathrm{~m}$ & 46.390 & 5.340 & 5.0 & 3.1 & 3.0 & 4 & $62.6 / 128.8$ \\
\hline 47 & 2003 & 12 & 9 & $18 \mathrm{~h} 03 \mathrm{~m}$ & 45.330 & 6.070 & 5.0 & 3.1 & 3.0 & 10 & $24.4 / 60.9$ \\
\hline 48 & 2003 & 12 & 20 & $03 \mathrm{~h} 29 \mathrm{~m}$ & 44.490 & 7.210 & 5.0 & 3.6 & 3.3 & 16 & $38.6 / 196.8$ \\
\hline 49 & 2003 & 12 & 21 & $01 \mathrm{~h} 35 \mathrm{~m}$ & 44.490 & 7.000 & 5.0 & 3.5 & 3.1 & 6 & $30.9 / 133.2$ \\
\hline 50 & 2004 & 1 & 28 & $20 \mathrm{~h} 09 \mathrm{~m}$ & 45.430 & 5.460 & 5.0 & 3.8 & 3.3 & 14 & $35.7 / 138.7$ \\
\hline 51 & 2004 & 2 & 18 & $14 \mathrm{~h} 26 \mathrm{~m}$ & 46.630 & 6.910 & 10.0 & 3.5 & 3.3 & 3 & $98.7 / 141.4$ \\
\hline 52 & 2004 & 2 & 18 & $14 \mathrm{~h} 31 \mathrm{~m}$ & 46.670 & 6.810 & 10.0 & 3.8 & 3.5 & 3 & $102.2 / 178.6$ \\
\hline 53 & 2004 & 5 & 8 & $12 \mathrm{~h} 38 \mathrm{~m}$ & 44.630 & 7.210 & 7.0 & 3.0 & 3.2 & 3 & $49.3 / 120.8$ \\
\hline 54 & 2004 & 5 & 14 & $00 \mathrm{~h} 30 \mathrm{~m}$ & 45.030 & 7.480 & 10.0 & 4.0 & 3.6 & 17 & $59.8 / 166.1$ \\
\hline 55 & 2005 & 9 & 8 & $11 \mathrm{~h} 27 \mathrm{~m}$ & 46.024 & 6.938 & -1.8 & 5.1 & 4.9 & 10 & $41.7 / 138.6$ \\
\hline
\end{tabular}

The number of accelerometric stations that recorded the event is indicated in the column entitled Number, and the distance range $\Delta_{\min }, \Delta_{\max }$ is in the last column. Magnitudes LDG and RéNaSS are the two local magnitudes used on the French territory. 
Table 4

Same as Table 3 for the Pyrenees Area

\begin{tabular}{|c|c|c|c|c|c|c|c|c|c|c|c|}
\hline \multirow[b]{2}{*}{ Event } & \multirow[b]{2}{*}{ Year } & \multirow{2}{*}{ Month } & \multirow[b]{2}{*}{ Day } & \multirow{2}{*}{ Time } & \multirow[b]{2}{*}{ Latitude $\left({ }^{\circ} \mathrm{N}\right)$} & \multirow[b]{2}{*}{ Longitude $\left({ }^{\circ} \mathrm{E}\right)$} & \multirow[b]{2}{*}{ Depth $(\mathrm{km})$} & \multicolumn{2}{|c|}{ Magnitudes } & \multirow[b]{2}{*}{ Number } & \multirow[b]{2}{*}{$\Delta(\mathrm{km}) \mathrm{Min} / \mathrm{Max}$} \\
\hline & & & & & & & & LDG & RéNaSS & & \\
\hline 1 & 2001 & 6 & 4 & $19 \mathrm{~h} 17 \mathrm{~m}$ & 43.007 & 0.160 & 11.4 & 3.6 & 3.6 & 3 & $48.7 / 190.2$ \\
\hline 2 & 2001 & 12 & 12 & $12 \mathrm{~h} 10 \mathrm{~m}$ & 43.121 & -1.079 & 8.4 & 3.3 & 3.5 & 3 & $30.0 / 91.7$ \\
\hline 3 & 2001 & 12 & 14 & $18 \mathrm{~h} 28 \mathrm{~m}$ & 42.828 & -0.814 & 8.9 & 3.5 & 3.6 & 4 & $30.8 / 69.2$ \\
\hline 4 & 2002 & 4 & 23 & $18 \mathrm{~h} 12 \mathrm{~m}$ & 42.827 & 0.701 & 5.9 & 2.9 & 3.0 & 3 & $40.4 / 68.0$ \\
\hline 5 & 2002 & 5 & 16 & $14 \mathrm{~h} 56 \mathrm{~m}$ & 42.929 & -0.146 & 9.5 & 4.8 & 4.8 & 7 & $20.4 / 171.4$ \\
\hline 6 & 2002 & 5 & 16 & $15 \mathrm{~h} 14 \mathrm{~m}$ & 42.932 & -0.144 & 7.1 & 4.4 & 4.2 & 6 & $20.0 / 171.2$ \\
\hline 7 & 2002 & 5 & 19 & $04 \mathrm{~h} 44 \mathrm{~m}$ & 42.975 & 0.140 & 12.5 & 3.8 & 3.8 & 10 & 17.6/197.9 \\
\hline 8 & 2002 & 6 & 11 & $18 \mathrm{~h} 56 \mathrm{~m}$ & 41.832 & 2.783 & 9.3 & 3.0 & 3.0 & 4 & $70.9 / 111.5$ \\
\hline 9 & 2002 & 6 & 13 & $10 \mathrm{~h} 42 \mathrm{~m}$ & 41.835 & 2.780 & 8.6 & 3.2 & 3.4 & 7 & $70.5 / 158.6$ \\
\hline 10 & 2002 & 6 & 21 & $02 \mathrm{~h} 26 \mathrm{~m}$ & 41.830 & 2.772 & 8.9 & 3.7 & 3.6 & 9 & $70.7 / 187.1$ \\
\hline 11 & 2002 & 7 & 8 & $09 \mathrm{~h} 46 \mathrm{~m}$ & 43.033 & -0.334 & 8.6 & 3.3 & 2.8 & 3 & $24.3 / 74.3$ \\
\hline 12 & 2002 & 12 & 9 & $13 \mathrm{~h} 44 \mathrm{~m}$ & 43.004 & 0.206 & 11.6 & 3.7 & 3.3 & 5 & 23.1/188.6 \\
\hline 13 & 2002 & 12 & 11 & $20 \mathrm{~h} 09 \mathrm{~m}$ & 43.090 & -0.364 & 11.8 & 4.3 & 4.4 & 5 & $25.7 / 156.1$ \\
\hline 14 & 2002 & 12 & 12 & $17 \mathrm{~h} 59 \mathrm{~m}$ & 43.080 & -0.272 & 8.8 & 4.9 & 4.6 & 5 & $18.3 / 114.8$ \\
\hline 15 & 2002 & 12 & 13 & $06 \mathrm{~h} 00 \mathrm{~m}$ & 43.085 & -0.280 & 8.9 & 3.3 & 2.9 & 4 & $18.9 / 149.3$ \\
\hline 16 & 2002 & 12 & 16 & $16 \mathrm{~h} 20 \mathrm{~m}$ & 42.545 & 0.325 & 8.8 & 3.3 & 3.3 & 5 & $44.4 / 172.4$ \\
\hline 17 & 2002 & 12 & 18 & $17 \mathrm{~h} 58 \mathrm{~m}$ & 42.993 & 0.210 & 13.0 & 3.2 & 2.4 & 3 & $23.2 / 108.2$ \\
\hline 18 & 2003 & 1 & 21 & $18 \mathrm{~h} 01 \mathrm{~m}$ & 43.071 & -0.335 & 9.1 & 4.6 & 4.4 & 5 & $23.5 / 153.4$ \\
\hline 19 & 2003 & 2 & 26 & $03 \mathrm{~h} 32 \mathrm{~m}$ & 42.301 & 2.208 & 8.1 & 4.4 & 4.1 & 11 & $22.9 / 191.9$ \\
\hline 20 & 2003 & 3 & 10 & oh54m & 42.300 & 2.220 & 7.3 & 3.1 & 3.0 & 5 & $38.9 / 103.1$ \\
\hline 21 & 2003 & 7 & 2 & $06 \mathrm{~h} 45 \mathrm{~m}$ & 42.570 & 1.965 & 4.2 & 3.3 & 3.3 & 3 & $75.6 / 99.9$ \\
\hline 22 & 2003 & 10 & 3 & $23 \mathrm{~h} 40 \mathrm{~m}$ & 42.714 & 2.064 & 11.1 & 3.5 & 3.5 & 9 & $37.8 / 157.1$ \\
\hline 23 & 2004 & 2 & 3 & $21 \mathrm{~h} 16 \mathrm{~m}$ & 42.557 & 0.845 & 11.2 & 3.7 & 3.7 & 10 & $50.7 / 186.4$ \\
\hline 24 & 2004 & 6 & 1 & $16 \mathrm{~h} 50 \mathrm{~m}$ & 42.292 & 2.223 & 7.2 & 4.4 & 4.1 & 4 & $76.2 / 118.9$ \\
\hline 25 & 2004 & 6 & 4 & $04 \mathrm{~h} 56 \mathrm{~m}$ & 42.296 & 2.225 & 7.4 & 3.5 & 3.6 & 3 & 75.9/103.2 \\
\hline 26 & 2004 & 9 & 18 & $12 \mathrm{~h} 52 \mathrm{~m}$ & 42.819 & -1.470 & 11.6 & 5.2 & 5.3 & 3 & $119.2 / 185.8$ \\
\hline 27 & 2004 & 9 & 21 & $15 \mathrm{~h} 48 \mathrm{~m}$ & 42.335 & 2.148 & 3.7 & 5.1 & 4.8 & 10 & $60.8 / 186.0$ \\
\hline 28 & 2004 & 9 & 23 & $09 \mathrm{~h} 58 \mathrm{~m}$ & 42.306 & 2.136 & 4.3 & 4.0 & 3.9 & 7 & $64.1 / 178.5$ \\
\hline
\end{tabular}

spectra down to $0.5 \mathrm{~Hz}$. For comparison, the spectra computed with 10 -sec time windows are plotted in Figure 4. Note that the difference in amplitude is due to the normalization by the window length. For the smallest distances, for which almost all the energy is present below $5 \mathrm{sec}$, a longest window will lead to smallest amplitudes because of the normalization, and this is true at least up to $100 \mathrm{~km}$ (see Fig. 4). For the largest distances, the difference in amplitude is less pronounced, and we decided to keep the 5-sec window because we do not want to include other phases than the direct $S$ waves in the analysis.

In what follows, we limit the inversion to frequencies lower than $15 \mathrm{~Hz}$ in order to avoid the strong attenuation at high frequency due to the shallow subsurface known as the $f_{\max }$ effect (Hanks, 1982). The final data sets consist in 352 spectra for 55 earthquakes and 31 stations for the Alps data set, and 156 spectra for 28 earthquakes and 18 stations for the Pyrenees data set.

\section{Inversion Method}

The $S$-wave displacement spectrum $A_{i j}\left(r_{i j}, f\right)$ can be written as the product of a source, a propagation, and a station term:

$$
A_{i j k}\left(r_{i j}, f_{k}\right)=\Omega_{i}\left(f_{k}\right) D_{i j}\left(r_{i j}, f_{k}\right) S_{j}\left(f_{k}\right),
$$

where $r_{i j}$ is the hypocentral distance from earthquake $i$ to station $j$, and $f_{k}$ is the frequency. We use the far-field displacement spectrum given by Brune's model (Brune, 1970, 1971):

$$
\Omega_{i}\left(f_{k}\right) \sim \frac{M_{0_{i}}}{\left[1+\left(f_{k} / f_{c_{i}}\right)^{2}\right]},
$$

where $M_{0_{i}}$ is the seismic moment, and $f_{c_{i}}$ is the corner frequency of event $i$. As a minimum distance of a few wavelengths is required for the far-field approximation to be valid (e.g., Aki and Richards, 2002), the use of frequencies down to $0.5 \mathrm{~Hz}$ (i.e., wavelengths up to $5 \mathrm{~km}$ ) imposes a minimum hypocentral distance of about $15 \mathrm{~km}$.

Attenuation involves anelastic decay and geometrical spreading:

$$
D_{i j}\left(r_{i j}, f_{k}\right)=\exp \left(-\frac{\pi r_{i j} f_{k}}{Q\left(f_{k}\right) v_{S}}\right) \times \frac{1}{r_{i j}^{\gamma}},
$$

where $v_{S}$ is the average $S$-wave velocity along the path, and $Q\left(f_{k}\right)=Q_{0} \times f_{k}^{\alpha}$ is the quality factor at frequency $f_{k}$. Note that the geometrical spreading is allowed to differ from the classical $r_{i j}^{-1}$ form.

$S_{j}\left(f_{k}\right)$ is the site effect at the station $j$. This term is equal to unity at each frequency in the absence of site effect (rock site conditions). 
(a)
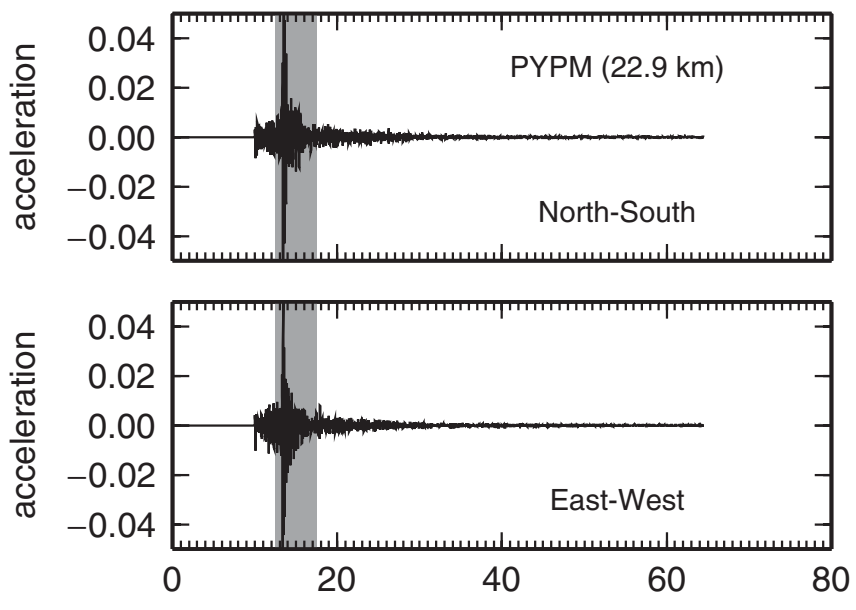

time (s)
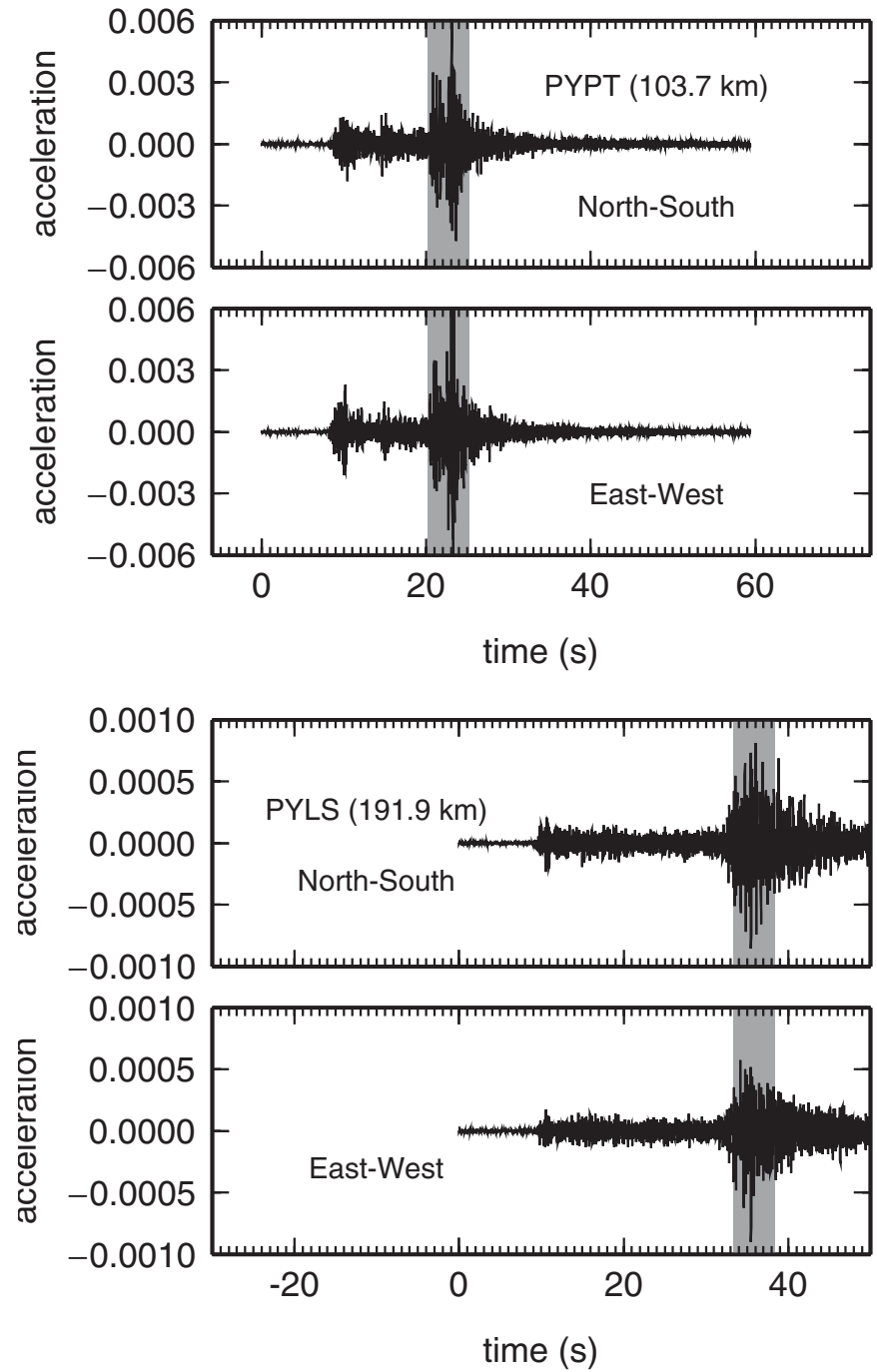

(b)
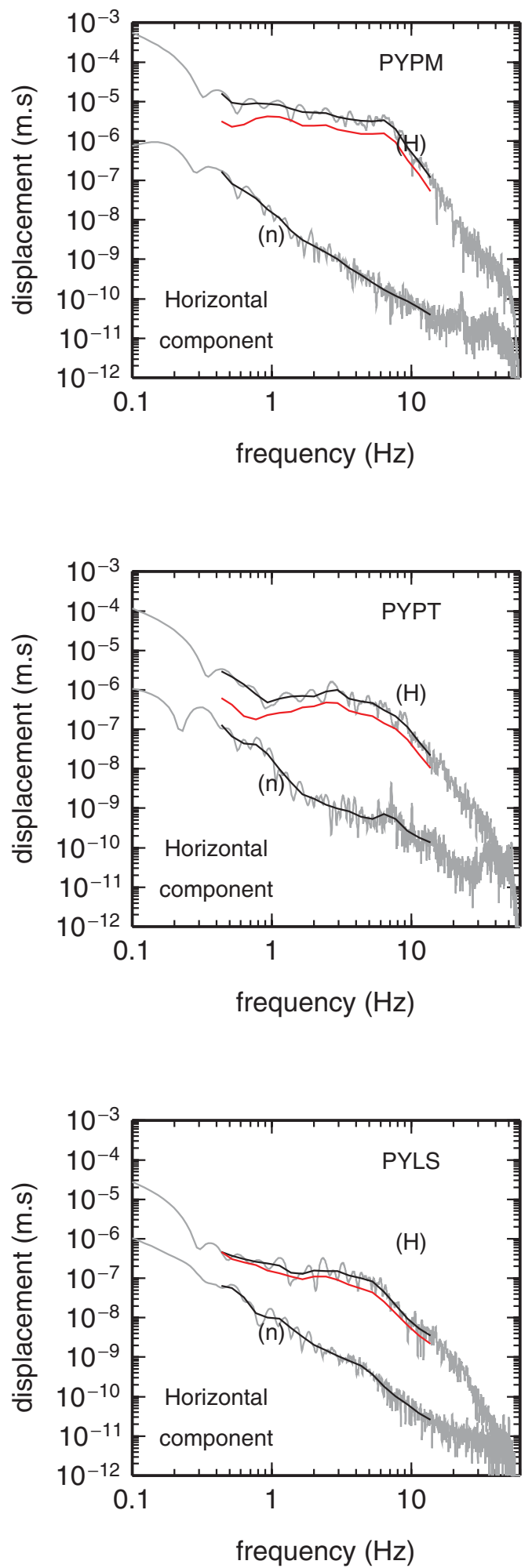

Figure 4. (a) Records of the acceleration for the east-west and north-south components of the 8 November 1997 earthquake (number 5 in Table 3) at the SAOF, CALF, and OGCA stations. The gray box shows the 5-sec time window used to compute the spectra. (b) Raw and smoothed Fourier spectra of the displacement for signal $(\mathrm{H})$ and noise $(\mathrm{n})$ for this event with 5-sec time window. The smoothed Fourier spectra computed using a 10-sec time window are also shown (red lines). 
Equation (2) may thus be written as

$$
\begin{aligned}
y_{i j k}= & m_{0_{i}}-\log _{10}\left[1+\left(\frac{f_{k}}{f_{c_{i}}}\right)^{2}\right]-\gamma \log _{10}\left(r_{i j}\right) \\
& -\frac{\pi r_{i j} f_{k}}{\log _{e}(10) Q_{0} f_{k}^{\alpha} v_{S}}+s_{j k},
\end{aligned}
$$

where

$$
\begin{gathered}
y_{i j k}=\log _{10}\left[A_{i j k}\left(r_{i j}, f_{k}\right)\right], \\
m_{0_{i}}=\log _{10}\left[M_{0_{i}} \times \frac{2 R_{\theta \phi}}{4 \pi \rho v_{S}^{3}}\right], \\
s_{j k}=\log _{10}\left[S_{j}\left(f_{k}\right)\right],
\end{gathered}
$$

with $R_{\theta \phi}$, the source radiation pattern, assumed to be constant $\left(R_{\theta \phi}=0.55\right.$ for $S$ waves; Boore and Boatwright, 1984), and $\rho$ and $\beta$ the density and the $S$-wave velocity of the medium at the source, respectively (we assume $\beta=v_{S}=3.5 \mathrm{~km} /$ $\sec ^{-1}$ and $\rho=2800 \mathrm{~kg} / \mathrm{m}^{-3}$ ). The factor 2 in equation (7) accounts for the free surface reflection at the station assuming a quasi-vertical incidence. This is exact for $S H$ and a reasonable approximation for $S V$ (Aki and Richards, 2002).

We have to solve a system of equations where the unknowns are the $m_{0_{i}}$ values (related to seismic moment) and the corner frequency $f_{c_{i}}$ for each event $i$, the site term $s_{j k}$ for each station $j$ and each frequency $f_{k}$, and the attenuation parameters $Q_{0}, \alpha$, and $\gamma$. We use an iterative Gauss-Newton method. Following Tarantola (2004), the perturbation of the model parameters at each iteration is given by

$$
\begin{aligned}
\Delta m= & m_{n+1}-m_{n} \\
= & \left(G_{n}^{t} C_{D}^{-1} G_{n}+C_{M}^{-1}\right)^{-1}\left\{G_{n}^{t} C_{D}^{-1}\left[g\left(m_{n}\right)-d_{\mathrm{obs}}\right]\right. \\
& \left.+C_{M}^{-1}\left(m_{n}-m_{\text {prior }}\right)\right\},
\end{aligned}
$$

where $m_{n}$ is the vector composed of the parameters at iteration $n$ and $G_{n}$ is the matrix composed of the partial derivatives of $y_{i j k}$ with respect to the current values of the parameters

$$
\begin{gathered}
\frac{\partial y_{i j k}}{\partial m_{0_{i}}}=1, \\
\frac{\partial y_{i j k}}{\partial f_{c_{i}}}=\frac{2 f_{k}^{2}}{\log _{e}(10) f_{c_{i}}\left(f_{c_{i}}^{2}+f_{k}^{2}\right)}, \\
\frac{\partial y_{i j k}}{\partial \gamma}=-\log _{10}\left(r_{i j}\right),
\end{gathered}
$$

$$
\begin{gathered}
\frac{\partial y_{i j k}}{\partial Q_{0}}=\frac{\pi r_{i j} f_{k}^{1-\alpha}}{\log _{e}(10) v_{S} Q_{0}^{2}}, \\
\frac{\partial y_{i j k}}{\partial \alpha}=\frac{\pi r_{i j} f_{k}^{1-\alpha} \log \left(f_{k}\right)}{\log _{e}(10) v_{S} Q_{0}},
\end{gathered}
$$

$$
\frac{\partial y_{i j k}}{\partial s_{j k}}=1 .
$$

$C_{D}$ and $C_{M}$ are the data and model covariance matrices, respectively, with $\left(C_{D}\right)_{i j}=\left(\sigma_{D}\right)_{i}^{2}=(0.2)^{2}$, where $i=1, \ldots$, number of data, and $\left(C_{M}\right)_{i j}=\left(\sigma_{M}\right)_{i}^{2}$, where $i=$ $1, \ldots$, number of parameters and the $\left(\sigma_{M}\right)_{i}$ are defined at the end of this paragraph, $g\left(m_{n}\right)$ is the vector composed of the $y_{i j k}$ calculated in the current model $m_{n}, d_{\mathrm{obs}}$ is the data vector, and finally, $m_{\text {prior }}$ is the vector composed of the starting values for the parameters.

Assuming that the parameters follow a Gaussian statistics and that the problem is not strongly nonlinear, we define the a posteriori covariance matrix (Tarantola, 2004):

$$
C_{M^{\prime}}=\left(G^{t} C_{D}^{-1} G+C_{M}^{-1}\right)^{-1}
$$

from which the correlation matrix is simply deduced by

$$
\operatorname{Corr}_{i j}=\frac{C_{M_{i j}^{\prime}}}{C_{M_{i i}^{\prime}} C_{M_{j j}^{\prime}}} .
$$

In addition, we need to remove a degree of freedom by imposing a constraint on the site responses (Boatwright et al., 1991; Field and Jacob, 1995). As shown by Bonilla et al. (1997), the mean response of a set of stations located on rock sites is a good reference. Because the stations under study have not been investigated yet, and because the geological map information is heterogeneous, the following method has been used to define our reference condition. A first inversion has been performed assuming that the mean of the whole set of stations is free of site effect at each frequency. We decided then to remove from the set of reference stations those showing amplification peaks or troughs compared to the mean. Then a second inversion was performed using this reference condition. We finally checked on the final results that the stations used in the reference still have a flat transfer function not too far from a theoretical rock-site response.

We define the starting model as follows. We compute $m_{0_{i}}$ from the RéNaSS magnitudes using the Hanks and Kanamori (1979) relationship

$$
m_{0_{i}}=\left[1.5 \times M_{\text {RéNaSS }}+9.1+\log _{10}\left(\frac{2 R_{\theta \phi}}{4 \pi \rho v_{S}^{3}}\right)\right] \pm 0.5
$$

and assume $f_{c_{i}}=6.5 \pm 6$, which covers the whole range of corner frequencies considering the magnitude range of the 
events analyzed, $s_{j k}=0 \pm 1$, and $\gamma=1 \pm 0.5$. The anelastic attenuation parameters are estimated for each region from Table 1 and from Drouet (2006) as $Q_{0}=300 \pm 300$ and $\alpha=0.5 \pm 0.5$. Thus, we explore a broad model space, but still the starting values must not be too far from the real values for the linearized inversion to be valid. We checked that the results of the inversion were not dependent on the starting model.

\section{Results}

\section{Correlation}

Correlation matrices are computed by linearizing the problem around the solution and are shown for the two data sets in Figure 5. The matrices are symmetric and organized from left to right and from bottom to top as follows: logarithm of seismic moments (columns 1-28 for the Pyrenees

(a)

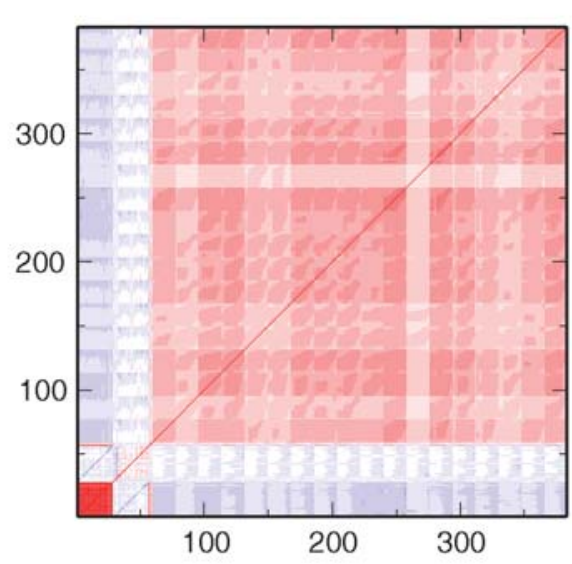

(b)

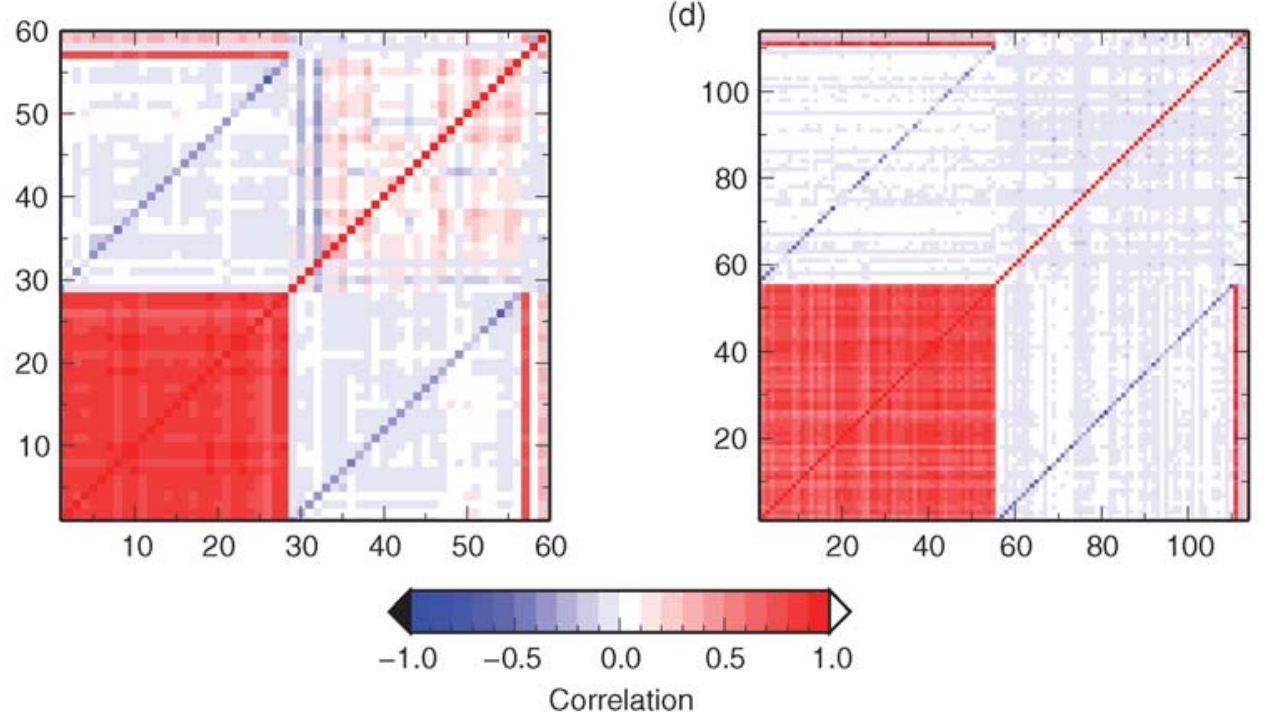

and 1-55 for the Alps), logarithm of corner frequencies (columns 29-56 for the Pyrenees and 56-111 for the Alps), attenuation parameters $\left(\gamma, Q_{0}\right.$, and $\left.\alpha\right)$ (columns 57-59 for the Pyrenees and 112-114 for the Alps), and site effects (columns 60-383 for the Pyrenees, 18 stations times 18 frequencies, and columns 115-671 for the Alps, 31 stations times 18 frequencies). The matrices at the bottom of Figure 5 correspond to a zoom on the logarithms of seismic moments, corner frequencies, and attenuation parameters. One can see that the correlation matrix is more complicated for the Pyrenees than for the Alps, but the general conclusions are the same. The attenuation parameters are strongly correlated to each other and are also correlated to the logarithms of seismic moments, which are also correlated to each other. As predicted from the source model, the logarithms of the seismic moments and the corner frequencies are negatively correlated (e.g., Brune, 1970, 1971; $M_{0} \propto f_{c}^{-3}$ ). The logarithms of

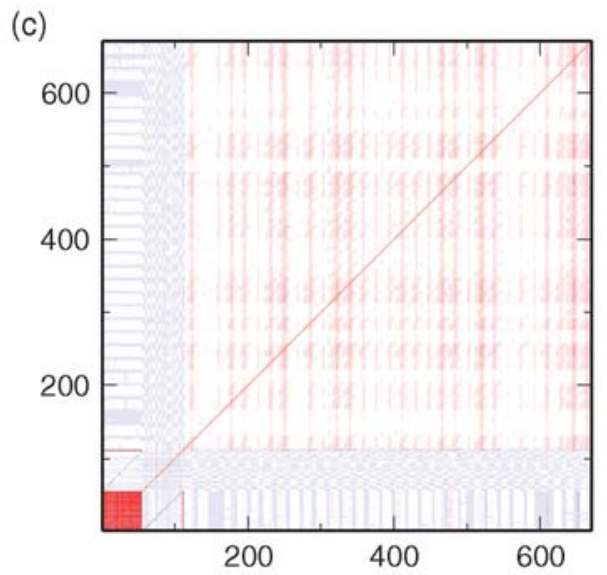

(d)

Figure 5. (a) Correlation matrix obtained for the inversion of the Pyrenean data. From left to right and bottom to top: $\log _{10} M_{0}$ ( 28 parameters), $\log _{10} f_{c}$ (28 parameters), attenuation parameters $\left(\gamma, Q_{0}, \alpha\right)$, and site effects (342 parameters). (b) Zoom on the lower left corner of (a). (c) Correlation matrix obtained for the inversion of the Alpine data. From left to right and bottom to top: $\log _{10} M_{0}$ (55 parameters), $\log _{10} f_{c}$ (55 parameters), attenuation parameters $\left(\gamma, Q_{0}, \alpha\right)$, and site effects (558 parameters). (b) Zoom on the lower left corner of (c). 
the site effects are only weakly correlated to the other parameters, especially for the Alps, and are correlated to each other in the case of the Pyrenees. We have also computed the model resolution matrices, which are shown for the two data sets on Figure 6. The trace of the matrix is equal to the number of parameters in both cases, and the offdiagonal elements are small, indicating that the parameters are resolved.

\section{Attenuation}

The results for the attenuation parameters are summarized in Table 1 and compared to the results from previous studies. Attenuation in the two regions is relatively different. The geometric attenuation seems to be higher in the Pyrenees $(\gamma=1.2)$ than in the Alps $(\gamma=1.0)$, while the anelastic attenuation is higher in the Alps, where the quality factor varies slowly with the frequency according to $Q(f)=322 \times f^{0.21}$, compared to $Q(f)=376 \times f^{0.46}$ for the Pyrenees.

(a)

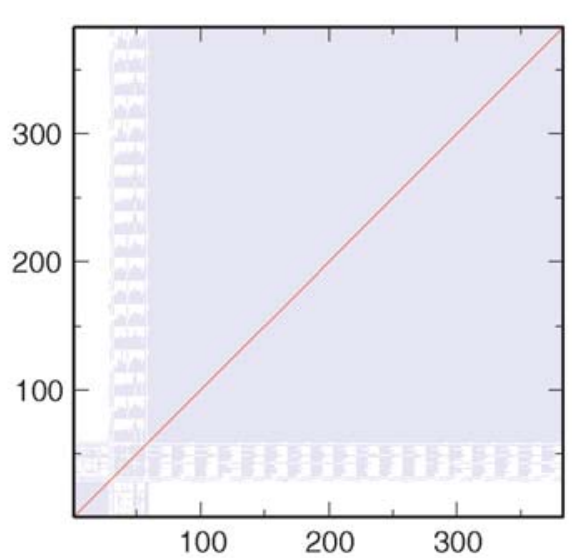

(b)

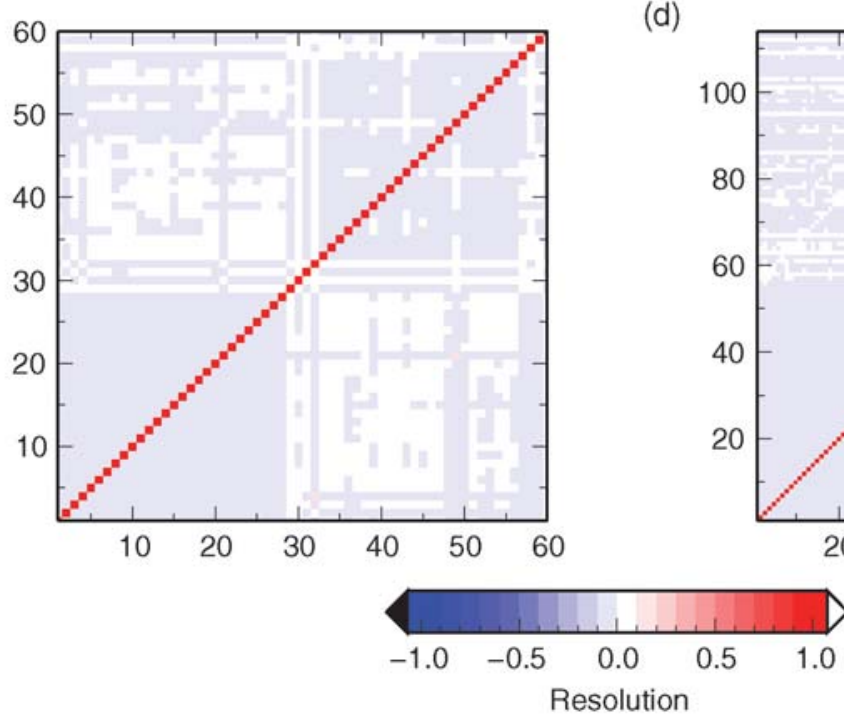

The value of $\gamma=1.2$ retrieved for the Pyrenees differs slightly from the usual value $\gamma=1$ obtained at teleseismic distances, but is comparable to values reported in other regional studies (Atkinson and Mereu, 1992; Malagnini and Herrmann, 2000; Bay et al., 2003; Atkinson, 2004). This difference is probably due to the attenuation by scattering, which is strong in the Pyrenees (e.g., Gagnepain-Beyneix, 1987), leading to a geometrical expansion slightly different than the one expected for body waves.

The a posteriori covariance matrix gives a very small standard deviation for attenuation parameters. Tests using different starting models give a more reliable estimation of standard deviation for the inverted parameters that are less than about $5 \%$ for $\gamma$, and less than $15 \%$ for $Q_{0}$ and $\alpha$. The values of $Q_{0}$ and $\alpha$ are compatible with previous results for France as shown in Table 1. The similarity of anelastic attenuation for $L g$ and $S g$ waves suggests that the quality factor obtained in both cases is related to shear waves (Campillo et al., 1985).

(c)

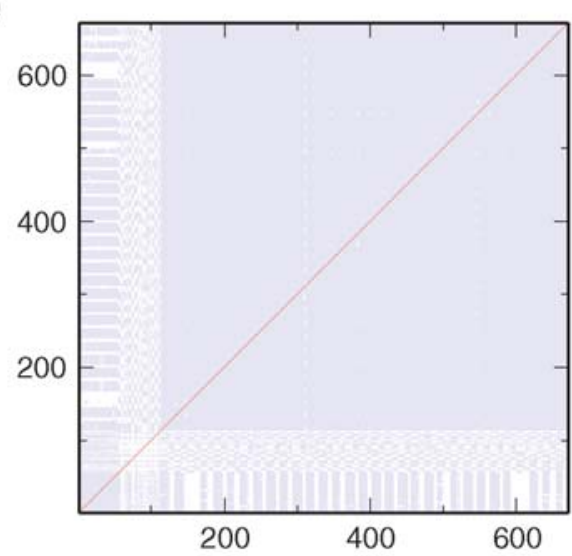

(d)

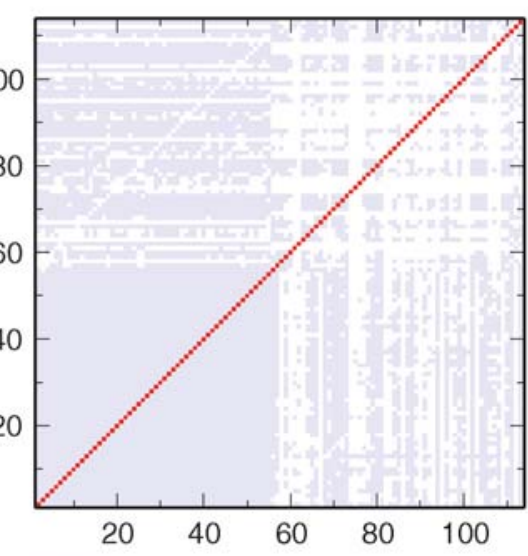

Figure 6. Same as Figure 5 but for the model resolution matrix. 


\section{Source Parameters}

In order to convert seismic moments into moment magnitudes, we use the relationship given by Hanks and Kanamori (1979):

$$
M_{\mathrm{w}}=\frac{\log _{10}\left(M_{0}\right)-9.1}{1.5},
$$

with $M_{0}$ in $\mathrm{N} \mathrm{m}$. Figure 7 shows moment magnitudes as a function of local magnitudes for all the events, with different symbols for the two regions. The moment magnitudes are compared to the local magnitudes $M_{\mathrm{LDG}}$ and $M_{\text {Rénass }}$. The results for the two regions are compatible, and we can define the following relationships:

$$
\begin{gathered}
M_{\mathrm{w}}=-0.27( \pm 0.19)+0.95( \pm 0.05) \times M_{\mathrm{LDG}}, \\
M_{\mathrm{w}}=-0.02( \pm 0.17)+0.93( \pm 0.05) \times M_{\text {RéNaSS }} .
\end{gathered}
$$

The corner frequencies are plotted as a function of the different magnitudes in Figure 8. We find the following linear relationships between $\log _{10}\left(f_{c}\right)$ and the magnitudes $M_{\mathrm{LDG}}, M_{\text {RéNaSS }}$, and $M_{\mathrm{w}}$ :

$$
\begin{aligned}
& \log _{10}\left(f_{c}\right)=1.74( \pm 0.03)-0.28( \pm 0.01) \times M_{\mathrm{LDG}} \\
& \log _{10}\left(f_{c}\right)=1.59( \pm 0.03)-0.26( \pm 0.01) \times M_{\text {RéNaSS }} \\
& \log _{10}\left(f_{c}\right)=1.72( \pm 0.03)-0.32( \pm 0.01) \times M_{\mathrm{w}}
\end{aligned}
$$

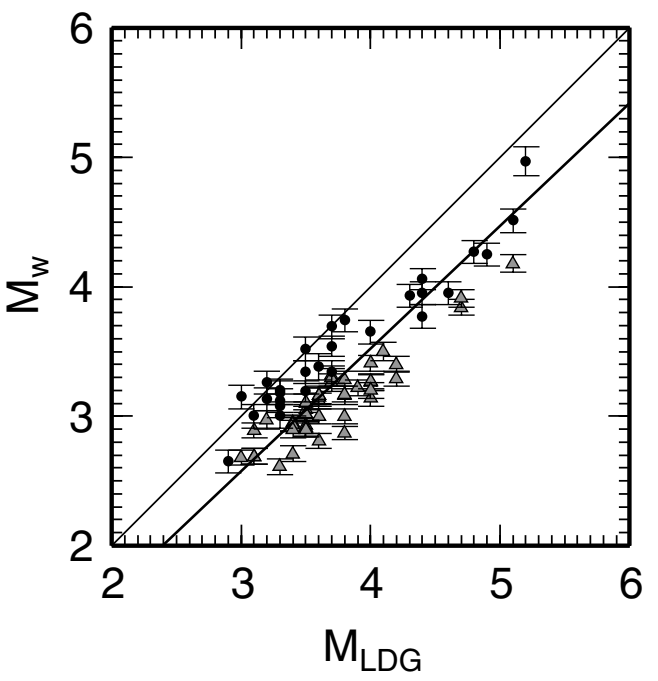

From a theoretical point of view, Deichmann (2006) shows that there should exist a one-to-one relationship between local magnitudes and moment magnitudes, or equivalently that the logarithms of the seismic moment should be proportional to 1.5 times the local magnitudes. However, observed relationships between the logarithms of the seismic moment and the local magnitudes give a slope lower than 1.5 (Deichmann, 2006). In this study, we find a slope of 1.45 (or 1.42) for the relationship between $\log _{10}\left(M_{0}\right)$ and $M_{\mathrm{LDG}}$ (or $M_{\mathrm{RéNaSS}}$ ). Concerning the relationship between the logarithms of the corner frequency and the moment magnitudes, theory predicts (Brune, 1970)

$$
\log _{10}\left(f_{c}\right) \propto-0.5 \times M_{\mathrm{w}}
$$

while we find a lower slope of -0.32 . This result can be compared to the relation of Drouet et al. (2005), and Chevrot and Cansi (1996) (Fig. 8), who find values of 0.25 and 0.35 , respectively.

Figure 9 shows the relationship between seismic moment and stress drop, which is computed from (Brune, 1970):

$$
\Delta \sigma=\frac{7}{16} M_{0}\left(\frac{f_{c}}{0.37 \beta}\right)^{3}
$$

The stress drops are scattered, but most of the values lie between $10^{5}$ and $10^{7} \mathrm{~Pa}$ (i.e., 1 and 100 bars). One can observe a slight tendency to higher stress drops for higher moments, but as suggested by Ide and Beroza (2001), this can be an effect of the finite-frequency bandwidth that we analyze.

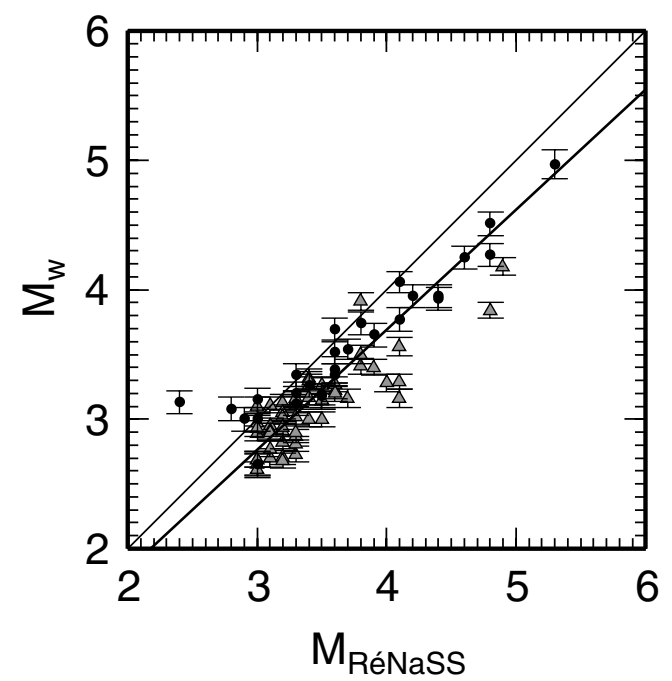

Figure 7. Comparison between moment magnitudes and local magnitudes. Pyrenees, black circles; Alps, gray triangles; One-to-one relationship, thin line; regression for the two data sets, solid line. Error bars are $1 \sigma$ confidence level. 
(a)

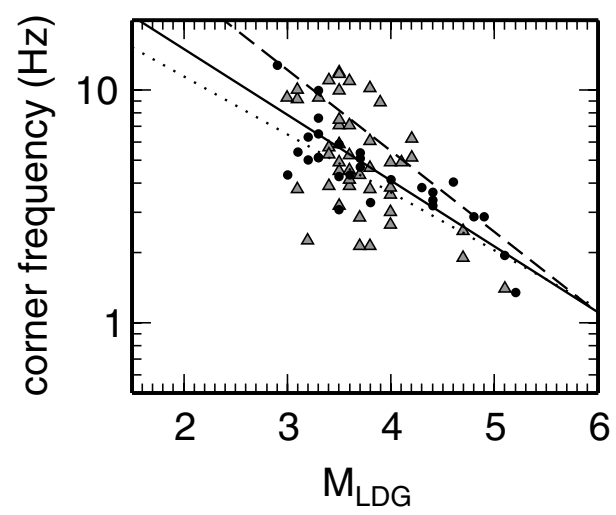

(b)

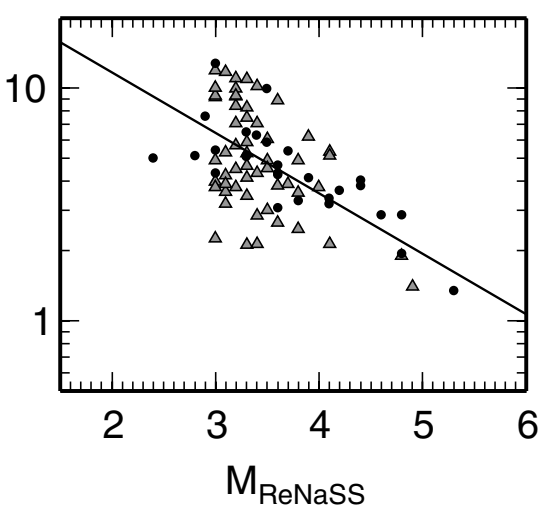

(c)

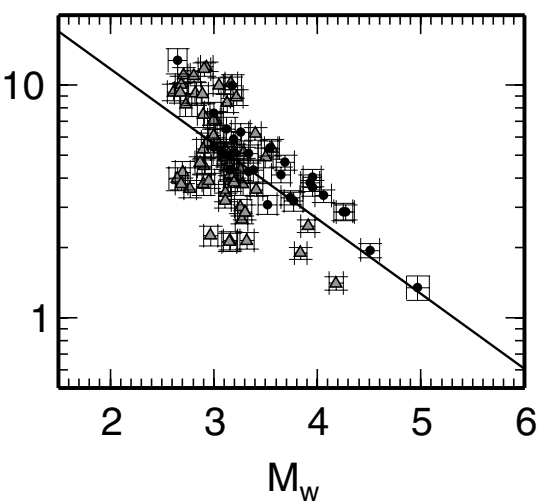

Figure 8. (a) Comparison between local LDG magnitudes and corner frequencies. Pyrenean data, black circles; Alpine data, gray triangles; regression of the two data sets, solid line. Dashed line is from Chevrot and Cansi (1996), and dotted line is from Drouet et al. (2005). (b) Same as (a) for local RéNaSS magnitudes. (c) Same as (a) for moment magnitudes. Error bars are $1 \sigma$ confidence level.

\section{Site Effects}

The site effects are the most robust results as indicated by their weak correlations to the other parameters. After a first inversion for which the mean logarithm of the site amplification factors over the whole set of stations was constrained to zero, we identify the stations showing site responses that are not flat and affected by large site effects described above and below the average (stations CALF, ESCA, ISOL, MENA, NROC, OGAG, OGAP, OGBL, OGCU, OGDH, OGFB, OGGM, OGMA, OGSR, OGTB,

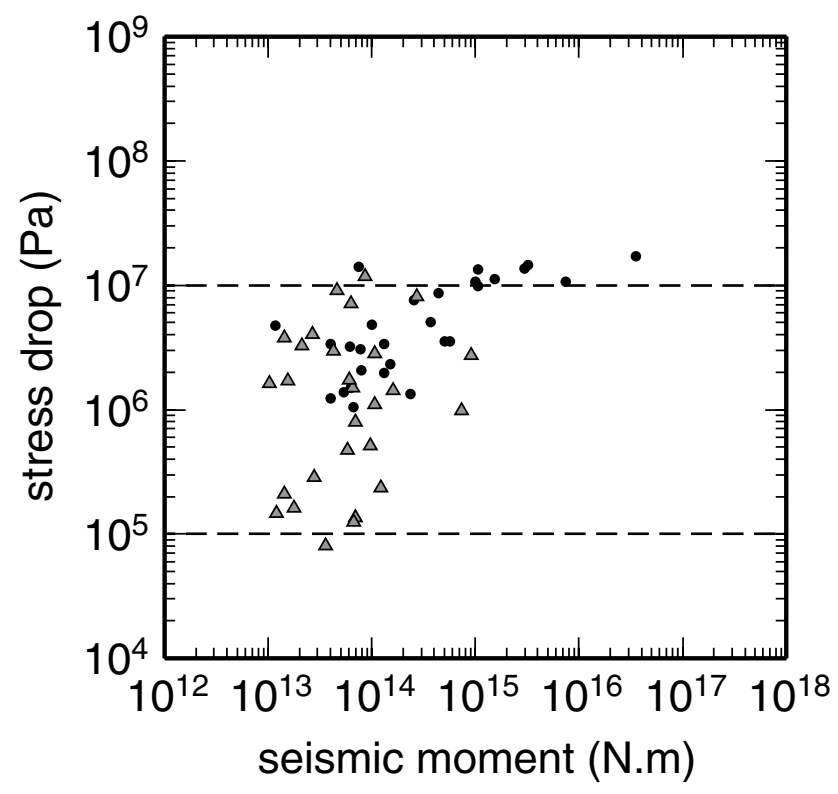

Figure 9. Comparison between seismic moments and stress drops. Pyrenean data, black circles; Alpine data, gray triangles. Dotted lines correspond to constant stress drops of $10^{5}$ and $10^{7} \mathrm{~Pa}$ (i.e., 1 and 100 bars). and SAOF in the Alps). A new closure condition was thus defined without those stations. The stations used in the reference are indicated by gray boxes in Figures 10 and 11 . Note that most of these stations are located on rock, according to geological maps, and only four of them are actually classified as sediment: OGPC for the Alps, and PYAS, PYFO, and PYLU for the Pyrenees; those stations are actually investigated. On the other hand, some stations classified as rock sites after geological maps show moderate to high amplifications (CALF, ESCA, ISOL, MENA, OGAG, OGGM, OGMA, and SAOF for the Alps) and thus were not used in the reference. With this new reference condition, the corner frequencies determined for the Alps are found systematically higher than before, while the other parameters are almost unchanged, except the site effects. We checked the influence of removing the stations with the highest and lowest amplitudes for the Pyrenees, but the results were unchanged between the different inversions indicating that there is no bias in the reference condition for this data set.

Site transfer functions for the stations under study are given in Figures 10 and 11. For the Pyrenees, Drouet et al. (2005) used a linear two-step inversion, assuming a constant quality factor and a grid search for the corner frequency, for computing the site response for the same stations. Their results are superimposed in Figure 11, showing a good agreement between the two methods. Figure 10 shows that strong site amplifications are found in sediment filled valleys as in Grenoble or Nice (stations OGCU, OGDH, and OGSR for Grenoble, and NROC for Nice, in Fig. 10). Significant amplifications can also affect stations identified as rock sites from geological maps and visual description of the sites (see Table 2, and Figs. 10 and 11). As shown by Steidl et al. (1996), near-surface weathering and cracking affect the recorded ground motion. Even stations located on rock sites may have significant site effects. Station OGFB has been considered to located on the free surface, while it is actually 

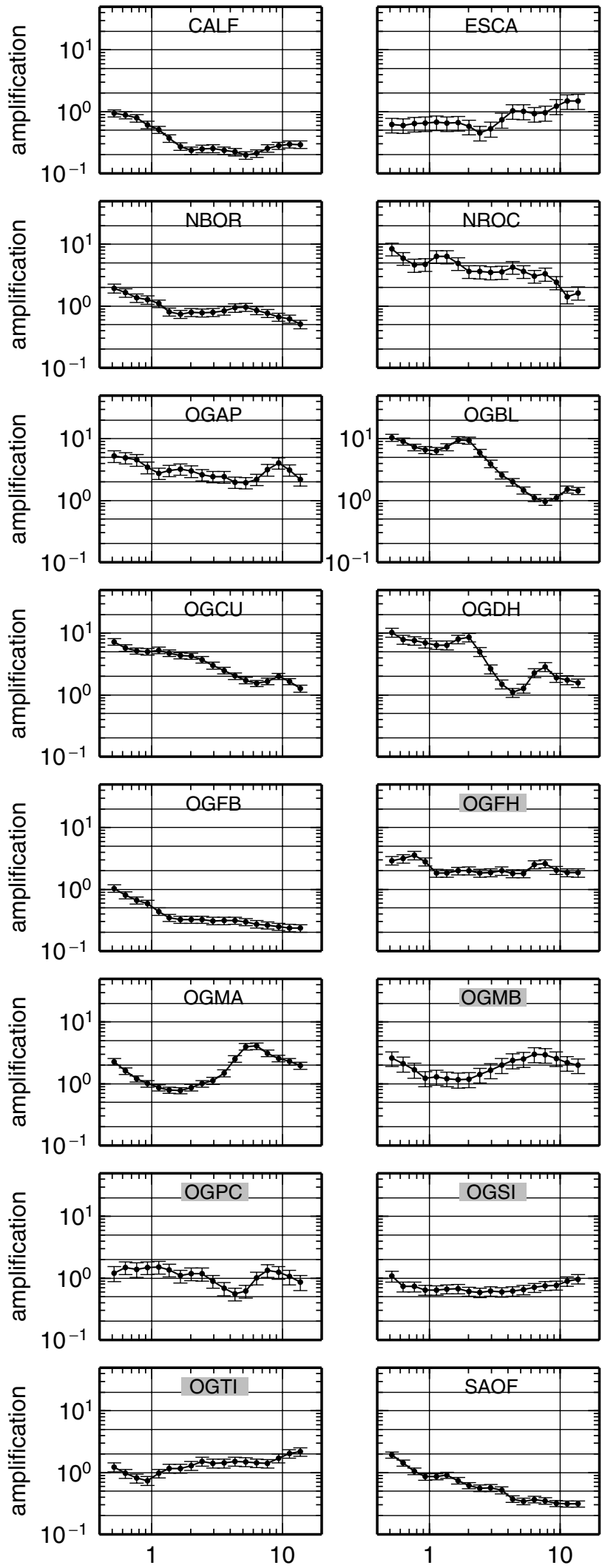

frequency $(\mathrm{Hz})$
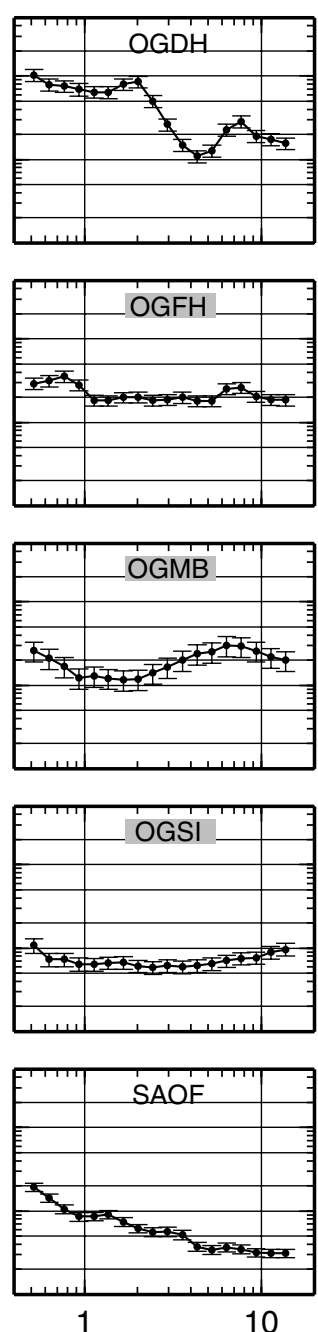

frequency $(\mathrm{Hz})$
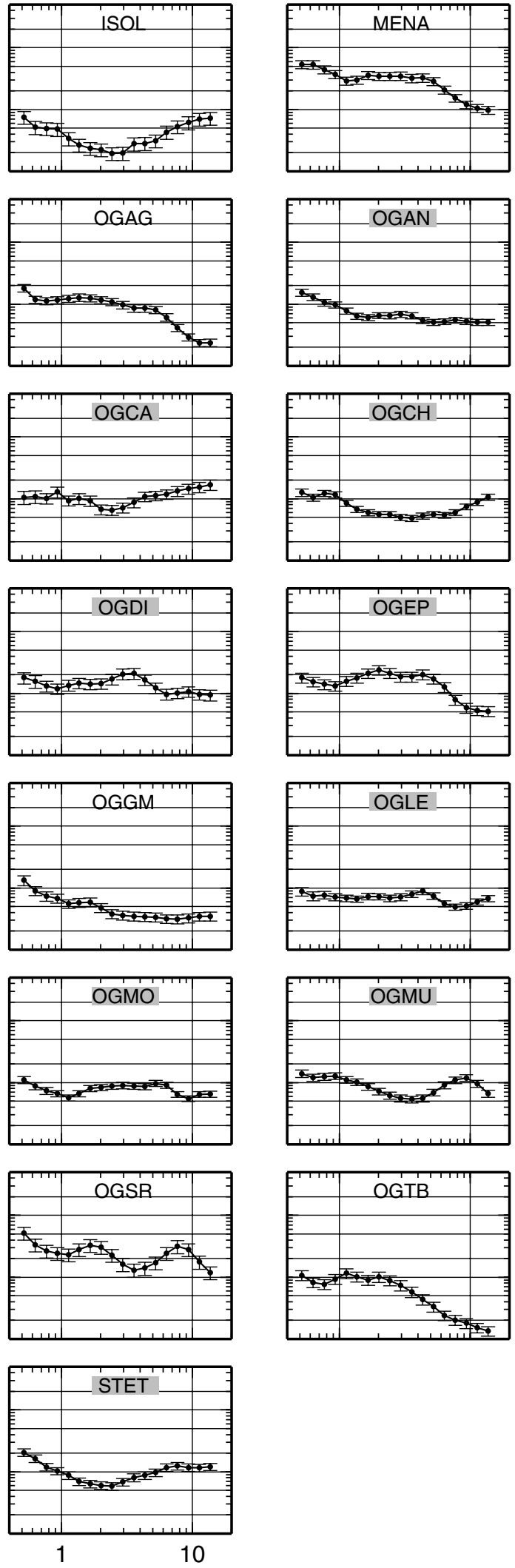

frequency $(\mathrm{Hz})$

Figure 10. Site effects for the Alpine RAP stations. Error bars are $1 \sigma$ confidence level. The stations with their names in a gray box are those used in the reference condition. 

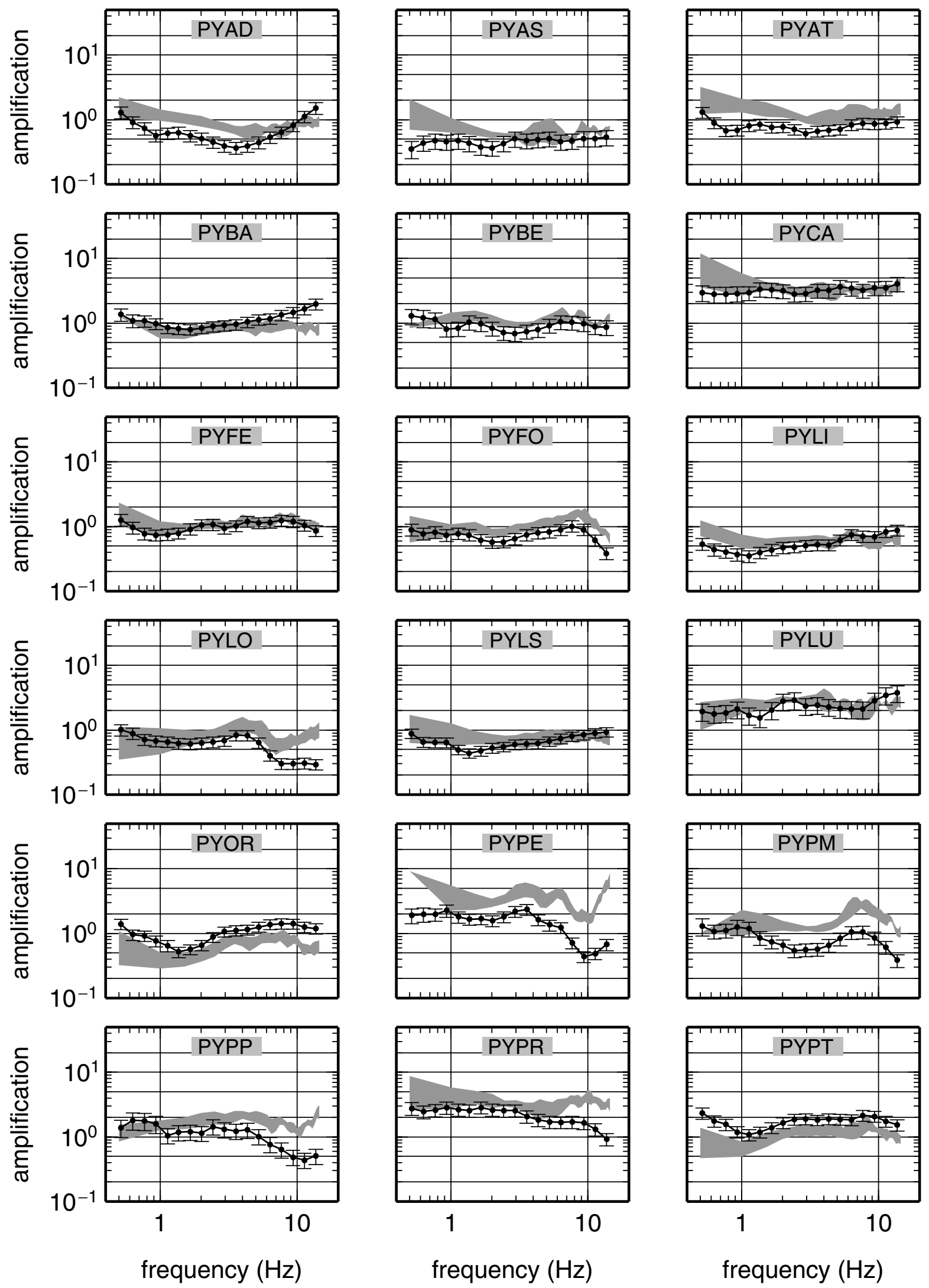

Figure 11. Site effects for the Pyrenean RAP stations. Error bars are $1 \sigma$ confidence level. Gray shaded areas are the results from Drouet et al. (2005) with $1 \sigma$ confidence interval. The stations with their names in a gray box are those used in the reference condition. 
located in a 500-m-deep borehole. Thus, OGFB site response must be multiplied by a factor of 2 to compensate for this effect.

Following Field and Jacob (1995) and Chávez-García et al. (1999), it is interesting to compare site effects derived from the inversion with those from other methods. Site effects derived from noise horizontal-to-vertical $(H / V)$ (Nakamura, 1989), earthquake $H / V$ (Lermo and Chávez-García, 1993), or spectral ratios with respect to a reference station, are available for some sites. Figure 12 presents this comparison for station PYLO in the Pyrenees and OGDH in the Alps. For better comparison, we have also inverted vertical component data. The results for the attenuation parameters and the source parameters are very close to those obtained from the horizontal component, but the site effects are different.

At the PYLO site, spectral ratios with reference station as well as $H / V$ ratios were computed for a velocimetric station (CHA) located a few meters away from PYLO by Dubos et al. (2003). The duration of the time windows they used to compute noise spectra was $30 \mathrm{sec}$, while for earthquake signals, windows begin at the $S$-wave arrival time and have a length dependent on magnitude and distance (a few seconds to 40-sec wide). At the OGDH site, the same methods were applied by P. Gueguen (personal comm., 2007), using also 30 -sec time windows to compute noise spectra, and for earthquake data, a window beginning with the $S$ waves and ending when the signal-to-noise ratio was too small. For the PYLO station, we plot on Figure 12 the horizontal site transfer function as well as the ratio between the horizontal and vertical transfer functions determined in this study. For the OGDH station, we plot the ratio between the horizontal transfer functions of stations OGDH and OGMU to be com- pared to the classical spectral ratio with reference station, and here again the ratio between the horizontal and vertical transfer functions for comparison with $H / V$ methods.

For PYLO, all the methods give similar results with a small increase in amplitude from 1 to $4 \mathrm{~Hz}$ followed by a sharp decrease up to $7 \mathrm{~Hz}$. This effect is probably due to topography because station PYLO is installed on the slope of a small hill of outcropping hard rock. At station OGDH, a strong amplification is observed at $2 \mathrm{~Hz}$, except with the $H / V$ noise method. Note the good agreement between the ratios OGDH/OGMU for the resonant frequency of the site effect, and the very good agreement between $H / V$ with earthquake data and the ratio between the horizontal and vertical site responses from our nonlinear inversion. The Grenoble basin is known to have a natural frequency of $0.3 \mathrm{~Hz}$ (Le Brun et al., 2001), which is outside the frequency range we investigated, and the observed resonant frequencies are probably multiples of this frequency or resonance inside superficial layers of sediments. The discrepancy between the results from noise measurement and earthquake data may be due to the fact that earthquake-generated waves produce resonance of the whole basin. Concerning the spectral ratios with reference station, the difference in amplitude can be explained by the longer windows used by P. Gueguen (personal comm., 2007), which probably include surface waves and therefore more energy.

In light of these results, we can identify stations with a flat response close to 1 and located with no ambiguity on rock according to geological maps (OGCA, OGLE, and OGSI for the Alps; PYAT, PYBE, and PYFE for the Pyrenees). We suggest that those stations are to be used as reference sites for the classical spectral ratio method.
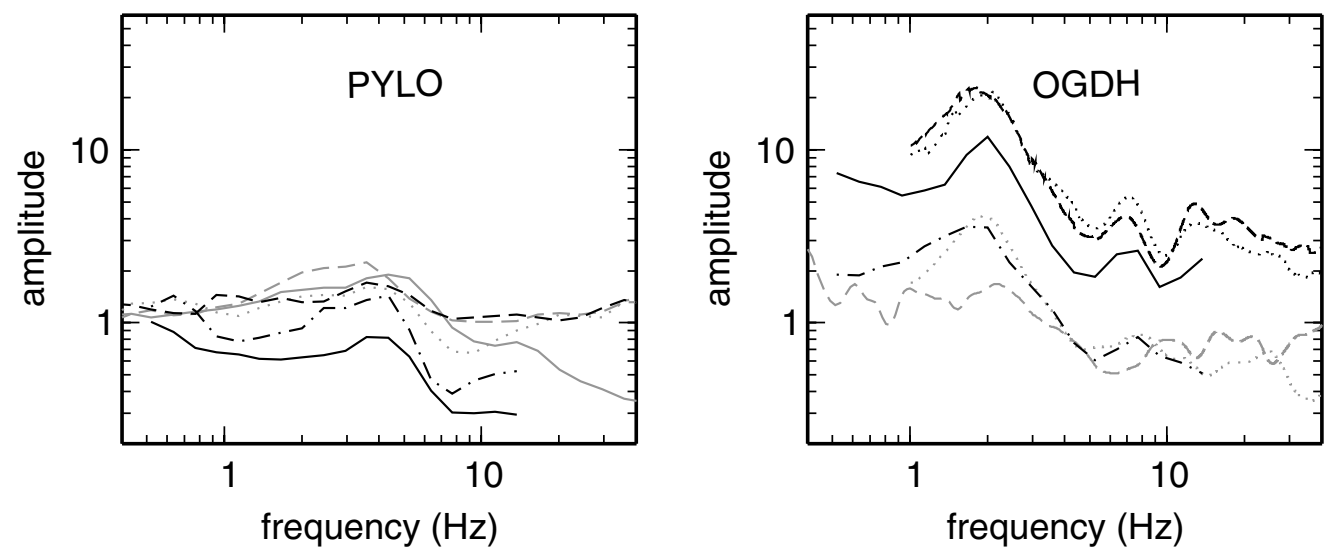

Figure 12. Site effects for the stations PYLO (Pyrenees) and OGDH (Alps) obtained with different methods. Left-hand side: PYLO horizontal site response from nonlinear inversion, solid black line; $H / V$ of noise at PYLO, dashed black line; ratio between horizontal and vertical site responses obtained in this study, dashed-dotted line; a station located a few meters away from PYLO, gray curves. (Spectral ratio with reference station, solid curves; $H / V$ of noise, dashed curves; $H / V$ of earthquake data, dotted curves; from Dubos et al., 2003). Right-hand side: ratio between OGDH and OGMU site responses from nonlinear inversion, solid black line; ratio between horizontal and vertical site responses from nonlinear inversion for station OGDH, dashed-dotted line; spectral ratios with OGMU as a reference, dotted and dashed black lines for east-west and north-south components, respectively; $H / V$ of noise, dashed gray line; and $H / V$ of earthquake data, dotted gray line. The last four results are from P. Gueguen (personal comm., 2007). 


\section{Discussion and Conclusions}

In order to check the results of the inversion, Figure 13a shows the histogram of the logarithms of amplitudes residuals (difference between the logarithms of observed and modeled amplitudes) for the two data sets. This distribution is close to a Gaussian with a small variance of about 0.2 . Our model is thus fitting the data rather well. Figure $13 \mathrm{~b}$ shows the same residuals but as a function of hypocentral distance. There is no apparent bias with distance in the results, suggesting that assuming a constant $\gamma$ is a reasonable assumption. Figure 14 shows the acceleration spectra after correction of attenuation and site effects for three events in each region, with different magnitudes, recorded over a wide range of distances, as well as the theoretical acceleration Brune spectra computed using the inverted seismic moments and corner frequencies for each event. The source spectra determined from the different stations are in good agreement, indicating that the Brune's model is adapted and that there is no obvious influence, in this frequency band, of the $f_{\max }$ effect (Hanks, 1982) in our data. Path and site effects can thus be used to invert directly for the source parameters, providing a convenient way to compute moment magnitudes, at least for the small to moderate events with sources that are described by the Brune's model.

The a posteriori correlation matrix suggests that (1) there is a strong trade-off between attenuation parameters, (2) this trade-off also affects seismic moments determination, and (3) on the other hand, the site effects are weakly correlated to the other parameters. In order to check the validity of the attenuation models that we derived for the Alps and the Pyrenees, we plot on Figure 15, for one earthquake in each region and three frequencies, the peak-ground acceleration computed from the filtered waveforms (butterworth filter of order 4), corrected for site effects (black and gray dots for east-west and north-south components, respectively). The black curves show the predicted attenuation using the

(a)

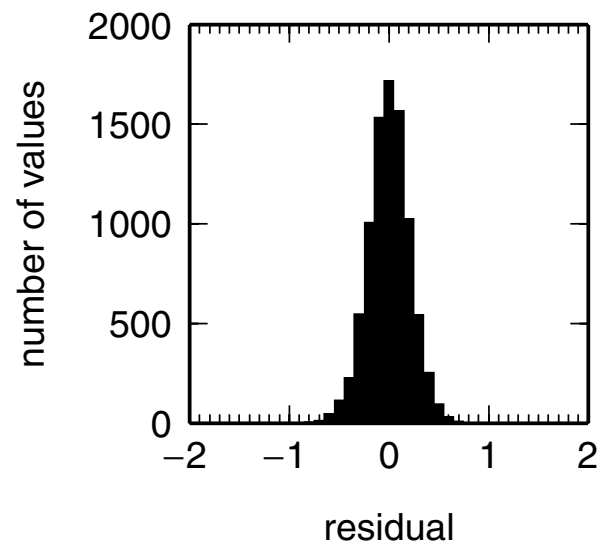

inverted attenuation parameters $\gamma, Q_{0}$, and $\alpha$ (see Table 1). One has to note that there is no amplitude scaling and that only the shape of the curves is relevant. There is a reasonable agreement between observed and modeled attenuation at each frequency.

The obtained $Q$-values $\left(Q_{0}\right.$ and $\left.\alpha\right)$ are compatible with other independent results for France (see Table 1). However, a low $Q_{0}$ is always counterbalanced by a high $\alpha$ (see, e.g., Gagnepain-Beyneix, 1987). This illustrates the trade-off between these parameters revealed by the correlation matrix. The shape of the spectra is also influenced by site effects, in particular the $f_{\max }$ frequency (Hanks, 1982). Its effect is limited here because we cut the high-frequency part of the spectra at $15 \mathrm{~Hz}$, but this also probably decreases our ability to resolve $Q$.

The frequency-independent attenuation (geometrical spreading) is represented by the $R^{-\gamma}$ term. We obtain a value for $\gamma$ close to one for the Alps, and slightly larger (1.2) for the Pyrenean data. Some weak-motion studies report similar results (Atkinson and Mereu, 1992; Malagnini and Herrmann, 2000; Bay et al., 2003; Atkinson, 2004). In these studies, the exponent of the geometrical decay is distance dependent to account for the different types of waves present in the signal. In our study, no distance dependence is observed, but our distance range is limited to $15-200 \mathrm{~km}$, and the window used to compute the spectra is such that it mostly includes $\mathrm{Sg}$ waves.

Another related problem concerns the influence of the scattering in the regions under study. Gagnepain-Beyneix (1987) analyzed coda waves in the Pyrenees and showed that scattering is the prevailing mechanism of attenuation below $10 \mathrm{~Hz}$. Moreover, the Alps and the Pyrenees seem to show strong spatial dependence of attenuation as indicated by the extinction of $L g$ waves for trans-Pyrenean and trans-Alpine paths (Campillo et al., 1993; Chazalon et al., 1993).

Crustal attenuation and amplification have not been taken into account in this study. As shown by Boore and Joy-

(b)

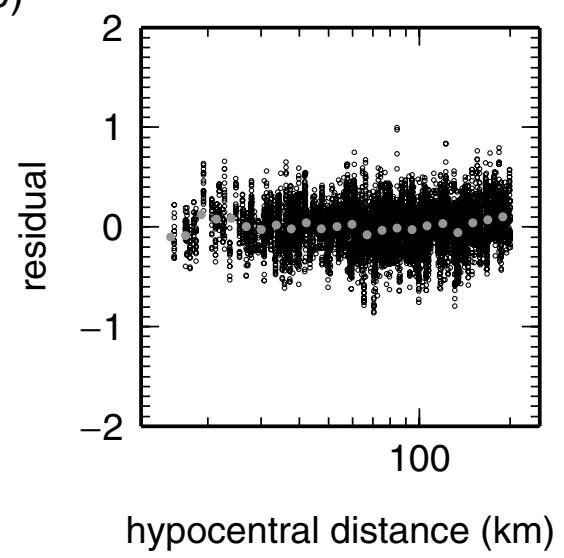

Figure 13. (a) Histogram of the residuals of the logarithms of amplitude spectra. (b) Residuals as a function of hypocentral distance, black dots; mean residual over distance bins, gray dots. 

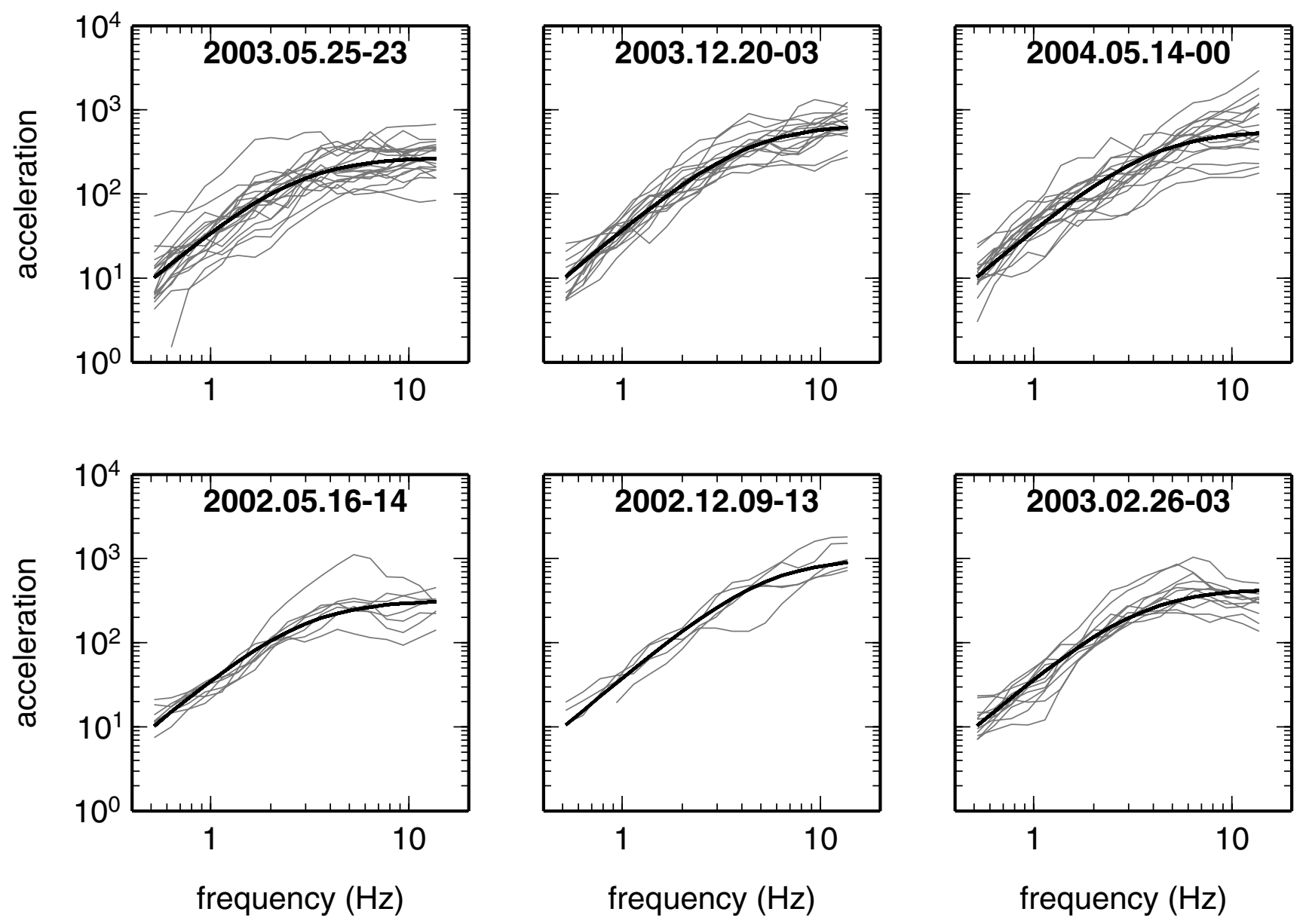

Figure 14. Acceleration spectra after correction of site and path effects (gray lines) for three events in each region (numbers 41, 48, and 54 in Table 3, and numbers 5, 12, and 19 in Table 4). The theoretical acceleration source spectra, according to the Brune's model, computed with the inverted seismic moments and corner frequencies for each event, are also shown (black lines).

ner (1997) a velocity gradient from a value of $3500 \mathrm{~m} / \mathrm{sec}$ in the vicinity of the source-to-rock velocity at the surface produces amplifications. For reasonable values of kappa, and a surface rock velocity of $620 \mathrm{~m} / \mathrm{sec}$, the combined effect of both attenuation and amplification peaks between about 2 and $5 \mathrm{~Hz}$ with a maximum level of less than 1.8, according to Boore and Joyner (1997). The surface velocities of rock stations in the Alps and the Pyrenees are still under investigation. Preliminary array measurements performed on some of these stations (e.g., OGMU) indicate a velocity between 1000 and $1500 \mathrm{~m} / \mathrm{sec}$ (P. Gueguen, personal comm., 2007). The combined effect of both crustal attenuation and amplification is then difficult to quantify but is probably less than 1.5. The source spectrum obtained in this study are the product of the Brune model and this neglected factor. Because high-frequency level scales with stress drop to the $2 / 3$ power, our obtained corner frequencies and stress drops are then higher than they would be if we had included this factor.

Another important result concerns the source characteristics. The Brune-type source model, which assumes a single corner frequency and a $f^{-2}$, fall-off seems realistic for the small earthquakes analyzed here. Our moment magnitudes scale with local magnitudes but are systematically lower (Fig. 7). Table 5 compares different moment magnitude estimations for the larger earthquakes of our data set. They are very close, although the methods used are different. The Eidgenössische Technische Hochschule Zürich (ETHZ), the U.S. Geological Survey, and Rueda and Mezcua (2005) and B. Delouis (personal comm., 2007) use a waveform inversion technique and thus low frequencies compared to our $0.5-15-\mathrm{Hz}$ band.

Finally, we computed stress drops between $10^{5}$ and $10^{7} \mathrm{~Pa}$ (i.e., 1 and 100 bars), which seem to be slightly dependent on seismic moment, a dependence that has also been observed by several authors (Atkinson, 1993; Kanamori et al., 1993; Abercrombie, 1995; Prejean and Ellsworth, 2001). Considering the dispersion in our data and recent studies on the influence of limiting the frequency bandwidth (Ide and Beroza, 2001), and of correlations between source, site, and propagation parameters in stress-drops estimates (Ide et al., 2003), this dependence could be an artifact. 

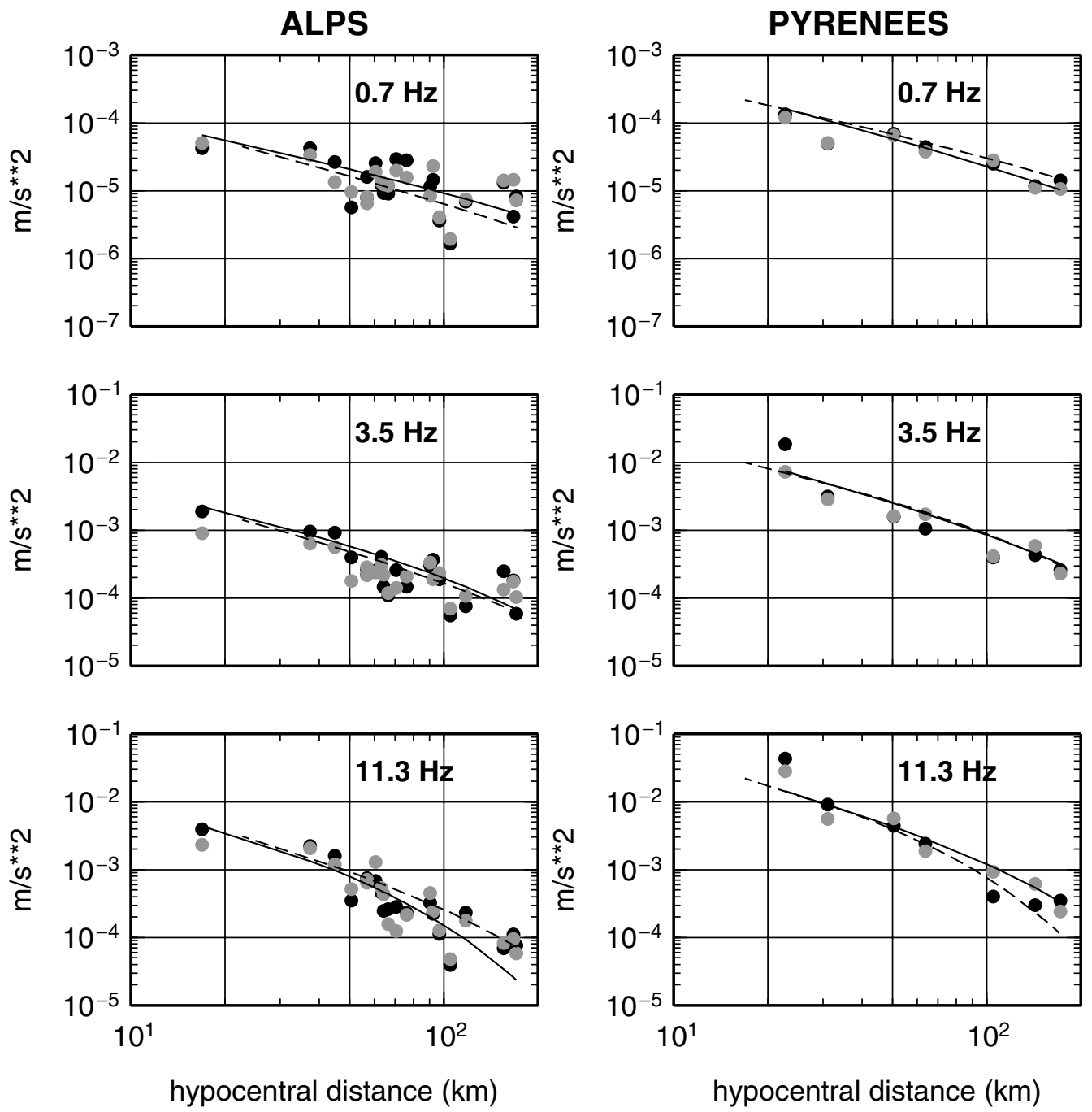

Figure 15. Peak ground acceleration from filtered time series around the central frequency indicated, divided by the corresponding site effect determined in this study for each station, for two earthquakes in the Alps and the Pyrenees (number 41, Table 3, and number 5, Table 4, respectively). East-west component, black dots; north-south component, gray dots. The black lines correspond to our models of attenuation using the parameters $\gamma, Q_{0}$, and $\alpha$ from Table 1, the solid one for the region considered, and the dashed line stands for the other region. Note that only the shape of the curves is relevant because there is no scaling in amplitude.

Moreover, recent studies have found that large earthquakes have a different behavior, which is probably related to the difference between earthquakes that do affect, and those that do not affect, the whole seismogenic zone (Mai and Beroza, 2000). However, studies using weak-motion attenuation models to predict moderate events use a scaling of stress drop with magnitude in order to explain the high frequency part of the earthquake spectra (Malagnini et al., 2002; Bay et al., 2005). Thus, the question of stress-drop scaling with magnitude still needs to be addressed.

Our approach also gives us site responses, and is an interesting alternative to other methods, such as the $H / V$

Table 5

Comparison of Moment Magnitude Determination from Different Institutes for a Selection of Events Used in This Study

\begin{tabular}{lclc}
\hline & ETHZ & \multicolumn{1}{c}{ Other } & This Study \\
\hline Event 5 in Table 4 & 3.9 & 3.6 (B. Delouis, personal comm., 2007) & 4.3 \\
Event 14 in Table 4 & 4.3 & 4.0 Rueda and Mezcua (2005) & 4.3 \\
Event 27 in Table 4 & 4.5 & & 4.5 \\
Event 55 in Table 3 & 4.5 & 4.3 (B. Delouis, personal comm., 2007) & 4.1 \\
\hline
\end{tabular}


method and the spectral ratio with a reference station. Site classifications for the building codes are generally based on the average first 30-m $S$-wave velocity, but as noted by Luzi et al. (2005), this is probably a rough approximation, and other information is required such as geomorphological conditions or depth of bedrock. The results presented here can probably help to refine the site classification of the French accelerometric stations based on the amplitude or the frequency of amplification observed in the transfer functions. Moreover, Luzi et al. (2005) also show that the transfer functions obtained by generalized inversion contain information on 2D and 3D site effects and thus provide better results than the $H / V$ method in the context of sedimentary basins.

\section{Acknowledgments}

We would like to thank the RAP teams for managing the network and making the data available. This work was supported by the Centre National de la Recherche Scientifique with funding from the French Environment Ministry. The work of one of the coauthors (F. Cotton) has been funded by the Interreg IIIB Sismovalp Project. Associate Editor Gail Atkinson and the two reviewers, Karen Assatourians and one anonymous reviewer, are gratefully thanked for their comments.

\section{References}

Abercrombie, R. E. (1995). Earthquake source scaling relationships from -1 to $5 M_{\mathrm{L}}$ using seismograms recorded at $2.5 \mathrm{~km}$ depth, J. Geophys. Res. 100, 24,015-24,036.

Aki, K., and P. G. Richards (2002). Quantitative Seismology, Second Ed., University Science Books, Sausalito, California, 700 pp.

Atkinson, G. M. (1993). Earthquake source spectra in eastern North America, Bull. Seismol. Soc. Am. 83, no. 6, 1778-1798.

Atkinson, G. M. (2004). Empirical attenuation of ground-motion spectral amplitudes in southeastern Canada and the northeastern United States, Bull. Seismol. Soc. Am. 94, no. 3, 1079-1095.

Atkinson, G. M., and R. F. Mereu (1992). The shape of ground motion attenuation curves in southeastern Canada, Bull. Seismol. Soc. Am. 82, no. 5, 2014-2031.

Bay, F., D. Fäh, L. Malagnini, and D. Giardini (2003). Spectral shear-wave ground-motion scaling in Switzerland, Bull. Seismol. Soc. Am. 93, no. 1, 414-429.

Bay, F., S. Wiemer, D. Fäh, and D. Giardini (2005). Predictive ground motion scaling in Switzerland: best estimates and uncertainties, J. Seism. 9, 223-240

Boatwright, J., J. B. Fletcher, and T. E. Fumal (1991). A general inversion scheme for source, site, and propagation characteristics using multiply recorded sets of moderate-sized earthquakes, Bull. Seismol. Soc. Am. 81, no. $5,1754-1782$.

Bonilla, L. F., J. H. Steidl, G. T. Lindley, A. G. Tumarkin, and R. J. Archuleta (1997). Site amplification in the San Fernando Valley, California: variability of site-effect estimation using the S-wave, coda and H/V methods, Bull. Seismol. Soc. Am. 87, no. 3, 710-730.

Boore, D., and J. Boatwright (1984). Average body-wave radiation coefficients, Bull. Seismol. Soc. Am. 74, no. 5, 1615-1621.

Boore, D. M., and W. B. Joyner (1997). Site amplifications for generic rock sites, Bull. Seismol. Soc. Am. 87, no. 2, 327-341.

Brune, J. N. (1970). Tectonic stress and the spectra of seismic shear waves from earthquakes, J. Geophys. Res. 75, no. 26, 4997-5009.

Brune, J. N. (1971). Correction, J. Geophys. Res. 76, no. 20, 5002.

Campillo, M., and J.-L. Plantet (1991). Frequency dependence and spatial distribution of seismic attenuation in France: experimental results and possible interpretations, Phys. Earth Planet. Interiors 67, 48-64.
Campillo, M., B. Feignier, M. Bouchon, and N. Béthoux (1993). Attenuation of crustal waves across the Alpine range, J. Geophys. Res. 98, no. B2, 1987-1996.

Campillo, M., J.-L. Plantet, and M. Bouchon (1985). Frequency-dependent attenuation in the crust beneath central France from Lg waves: data analysis and numerical modelling, Bull. Seismol. Soc. Am. 75, no. $5,1395-1411$.

Castro, R. R., H. Fabriol, M. Bour, and B. L. Brun (2003). Attenuation and site effects in the region of Guadeloupe, Lesser Antilles, Bull. Seismol. Soc. Am. 93, no. 2, 612-626.

Castro, R. R., F. Pacor, D. Bindi, G. Franceschina, and L. Luzi (2004). Site response of strong ground motion stations in the Umbria, central Italy, region, Bull. Seismol. Soc. Am. 94, no. 2, 576-590.

Chávez-García, F. J., W. R. Stephenson, and M. Rodríguez (1999). Lateral propagation effects observed at Parkway, New Zealand. A case history to compare 1D versus 2D site effects, Bull. Seismol. Soc. Am. 89, no. 3, $718-732$.

Chazalon, A., M. Campillo, R. Gibson, and E. Carreno (1993). Crustal wave propagation anomaly across the Pyrenean range. Comparison between observations and numerical simulations, Geophys. J. Int. 115, 829-838.

Chevrot, S., and Y. Cansi (1996). Source spectra and site-response estimates using the coda of Lg waves in western Europe, Geophys. Res. Lett. 23, no. $13,1605-1608$.

Deichmann, N. (2006). Local magnitude, a moment revisited, Bull. Seismol. Soc. Am. 96, no. 4A, 1267-1277, doi 10.1785/0120050115.

Drouet, S. (2006). Analyse des données accélérométriques pour la caractérisation de l'aléa sismique en France métropolitaine, Thèse de Doctorat, Université Paul Sabatier, Toulouse III, France.

Drouet, S., A. Souriau, and F. Cotton (2005). Attenuation, seismic moment, and site effects for weak-motion events: application to the Pyrenees, Bull. Seismol. Soc. Am. 95, no. 5, 1731-1748.

Dubos, N., A. Souriau, C. Ponsolles, J. F. Fels, and G. Sénéchal (2003). Etudes des effets de sites dans la ville de Lourdes (Pyrénées, France) par la méthode des rapports spectraux, Bull. Soc. Géol. Fr. 174, no. 1, 33-44.

Eva, C., M. Cattaneo, P. Augliera, and M. Pasta (1991). Regional coda Q variations in the western Alps (northern Italy), Phys. Earth Planet. Interiors $\mathbf{6 7}, 76-86$.

Field, E. H., and K. H. Jacob (1995). A comparison and test of various siteresponse estimation techniques, including three that are not referencesite dependent, Bull. Seismol. Soc. Am. 85, no. 4, 1127-1143.

Frankel, A., D. Carver, E. Cranswick, M. Meremonte, T. Bice, and D. Overturf (1999). Site response for Seattle and source parameters of earthquakes in the Puget Sound region, Bull. Seismol. Soc. Am. 89, no. 2, 468-483.

Gagnepain-Beyneix, J. (1987). Evidence of spatial variations of attenuation in the western Pyrenean range, Geophys. J. R. Astr. Soc. 89, 681-704.

Hanks, T. C. (1982). $f_{\max }$, Bull. Seismol. Soc. Am. 72, no. 6, 1867-1879.

Hanks, T. C., and H. Kanamori (1979). A moment magnitude scale, $J$. Geophys. Res. 84, no. B5, 2348-2350.

Herráiz, M., and J. Mezcua (1984). Application of coda wave analysis to microearthquake analog data, Ann. Geophys. 2, no. 5, 545-552.

Ide, S., and G. C. Beroza (2001). Does apparent stress vary with earthquake size?, Geophys. Res. Lett. 28, no. 17, 3349-3352.

Ide, S., G. C. Beroza, S. G. Prejean, and W. L. Ellsworth (2003). Apparent break in earthquake scaling due to path and site effects on deep borehole recordings, J. Geophys. Res. 108, no. B5, 2271, doi 10.1029/ 2001 JB001617.

Kanamori, H., J. Mori, E. Hauksson, T. H. Heaton, L. K. Hutton, and L. M. Jones (1993). Determination of earthquake energy release and $M_{\mathrm{L}}$ using Terrascope, Bull. Seismol. Soc. Am. 83, no. 2, 330-346.

Lambert, J., and A. Levret-Albaret (1996). Mille Ans de Séismes en France, Ouest Ed., Presses Académiques, France.

Le Brun, B., D. Hatzfeld, and P. Y. Bard (2001). Site effect study in urban area: experimental results in Grenoble (France), Pure Appl. Geophys. 158, 2543-2557. 
Lermo, J., and F. J. Chávez-García (1993). Site effect evaluation using spectral ratios with only one station, Bull. Seismol. Soc. Am. 83, 1574-1594.

Luzi, L., D. Bindi, G. Franceschina, F. Pacor, and R. R. Castro (2005) Geotechnical site characterisation in the Umbria-Marche area and evaluation of earthquake site response, Pure Appl. Geophys. 162, 2133-2161.

Mai, P. M., and G. C. Beroza (2000). Source scaling properties from finitefault-rupture models, Bull. Seismol. Soc. Am. 90, no. 3, 604-615.

Malagnini, L., and R. B. Herrmann (2000). Ground-motion scaling in the region of the 1997 Umbria-Marche earthquake (Italy), Bull. Seismol. Soc. Am. 90, no. 4, 1041-1051.

Malagnini, L., A. Akinci, R. B. Hermann, N. A. Pino, and L. Scognamiglio (2002). Characteristics of the ground motion in northeastern Italy, Bull. Seismol. Soc. Am. 92, no. 6, 2186-2204.

Modiano, T., and D. Hatzfeld (1982). Experimental study of the spectra content for shallow earthquakes, Bull. Seismol. Soc. Am. 72, no. 5, $1739-1758$

Nakamura, Y. (1989). A method for dynamic characteristics estimations of subsurface using microtremors on the ground surface $Q$, Rep. Railw. Tech. Res. Inst., Jpn. 30, 25-33.

Nicolas, M., B. Massinon, P. Mechler, and M. Bouchon (1982). Attenuation of regional phases in western Europe, Bull. Seismol. Soc. Am. 72, no. 6 , 2089-2106.

Nocquet, J., and E. Calais (2003). Crustal velocity field of western Europe from permanent GPS array solutions, 1996-2001, Geophys. J. Int. 154, $72-88$.

Prejean, S., and W. L. Ellsworth (2001). Observations of earthquake source parameters at $2 \mathrm{~km}$ depth in the Long Valley caldera, eastern California, Bull. Seismol. Soc. Am. 91, no. 2, 165-177.

Rueda, J., and J. Mezcua (2005). Near-real-time seismic moment-tensor determination in Spain, Seismol. Res. Lett. 76, no. 4, 455-465.

Scherbaum, F., and M. Wyss (1990). Distribution of attenuation in the Kaoiki, Hawaii, source volume estimated by inversion of $\mathrm{P}$ wave spectra, J. Geophys. Res. 95, no. B8, 12,439-12,448.
Scherbaum, F., F. Cotton, and P. Smit (2004). On the use of response spectral-reference data for the selection and ranking of ground-motion models for seismic-hazard analysis in regions of moderate seismicity: The case of rock motion, Bull. Seismol. Soc. Am. 94, no. 6, 2164-2185.

Seekins, L. C., Wenneberg, L., Margheriti, L., Liu, and H.-P. (1996). Site amplification at five locations in San Fransisco, California: a comparison of S waves, codas, and microtremors, Bull. Seismol. Soc. Am. 86, no. 3, 627-635.

Semblat, J.-F., A.-M. Duval, and P. Dangla (2000). Numerical analysis of seismic wave amplification in Nice (France) and comparisons with experiments, Soil Dyn. Earthq. Eng. 19, 347-362.

Steidl, J. H., A. G. Tumarkin, and R. J. Archuleta (1996). What is a reference site?, Bull. Seismol. Soc. Am. 86, no. 6, 1733-1748.

Tarantola, A. (2004). Inverse Problem Theory and Methods for Model Parameters Estimation, SIAM, Philadelphia.

Thouvenot, F. (1983). Frequency dependence of the quality factor in the upper crust: a deep seismic sounding approach, Geophys. J. R. Astr. Soc. 73, 427-447.

Laboratoire de Dynamique Terrestre et Planétaire

Observatoire Midi-Pyrénées

14, Avenue Edouard Belin

31400 Toulouse, France

(S.D., S.C., A.S.)

Laboratoire de Géophysique Interne et Tectonophysique

Observatoire de Grenoble

Université Joseph Fourier, CNRS

BP 53X

38041 Grenoble Cedex, France

(F.C.)

Manuscript received 19 October 2006 